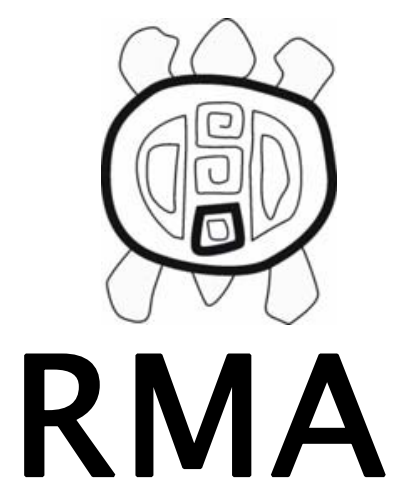

Antropología Social

\title{
La aldea en la ciudad. Ecos urbanos de un debate antropológico
}

\author{
Adrián Gorelik \\ Universidad Nacional de Quilmes / CONICET \\ adrian.gorelik@gmail.com
}

\section{Resumen}

El artículo busca mostrar los diálogos del pensamiento urbano latinoamericano con un famoso debate antropológico, el del «continuo folk-urbano» de Robert Redfield y «la cultura de la pobreza» de Oscar Lewis. El impacto que Redfield y, más en general, las teorías de Chicago sobre el cambio social tuvieron en las teorías de la modernización latinoamericana es, por supuesto, bien conocido, así como también los trabajos de Lewis. Pero no se ha reflexionado lo suficiente sobre el significado de que todo el pensamiento urbano latinoamericano se haya desenvuelto, en el período que corre entre la Segunda Guerra y los años setenta, en el marco puesto por aquel debate. Y como la ciudad tuvo, en ese período, una sobredeterminación política y cultural evidente, revisar la conexión con aquel debate antropológico no supone solamente el análisis de un caso entre otros de circulación de las ideas científicas, sino la posibilidad de entrever, a través de la antropología, el espectro de figuraciones dentro del cual se movió entonces el pensamiento sobre la «ciudad latinoamericana».

Palabras clave: pensamiento urbano, Latinoamérica, circulación de ideas.

The village in the city. Urban echoes of an anthropological debate

\begin{abstract}
The article aims to show the dialogues of the Latin American urban thought with a famous anthropological debate, that of Robert Redfield's «folk-urban continuum» and Oscar Lewis 's «culture of poverty». The impact that Redfield and, more broadly, Chicago's theories on social change had on the theories of modernization in Latin America is of course well known, as well as the works of Lewis. But it has not been reflected enough about the meaning that the whole Latin American urban thought has been developed, in the period that runs between the Second War and the seventies, under the framework established by that debate. And as the city had, in that period, a clear political and cultural overdetermination, reviewing the connection with that debate is not only the analysis of a case among others of circulation of scientific ideas, but the opportunity to observe, through anthropology, the spectrum of figurations within which the thinking about the «Latin American city» then moved.
\end{abstract}

Keywords: urban thinking, Latin-America, ideas circulation.

1. Las relaciones entre antropología y pensamiento urbano son muy anteriores a la existencia de la antropología urbana como subdisciplina $-y$, en verdad, una vez que ésta surgió ya casi no continuó el diálogo, porque su propia aparición fue el resultado de un distanciamiento crítico de la visión modernizadora-planificadora que destacó en el pensamiento urbano.' Son, por supuesto, muy conocidos los orígenes «etnográficos» de la sociología urbana en Chicago y el fuerte impacto de algunos de los presupuestos de esa escuela de pensamiento en las concepciones dominantes sobre las relaciones entre ciudad y modernidad durante buena parte del siglo XX, en especial, en las teorías de la modernización discutidas en el ámbito latinoamericano. ${ }^{2}$ Podría decirse que la teoría del desarrollo necesitaba, por definición, una concepción del cambio social y-como señaló Alejandro Blanco (2003: 691)- las «teorías de matriz antropológica» de Chicago eran entonces las que respondían más adecuadamente a ello, especialmente, la teoría del "continuo folkurbano» de Robert Redfield, uno de los autores que trataremos aquí. Todo esto es muy conocido: no sólo porque figura en los manuales de la 
segunda mitad del siglo XX como un momento fundamental tanto de la sociología como de la antropología, y como antecedente directo de sus respectivas subespecies urbanas, sino también porque, luego de décadas de desprestigio teórico e ideológico, ha comenzado ya hace algún tiempo un renovado interés por estos clásicos del pensamiento social, derivado fundamentalmente del nuevo ciclo de interrogación sobre la modernidad que se ha abierto en los años ochenta -pese a lo cual, conviene aclarar, sigue sin haber buenas ediciones en español de las obras canónicas del período «heroico» de Chicago, empezando por The City, de Robert Park, Ernst Burgess y Roderick McKenzie. ${ }^{3}$

Pero si la larga hegemonía del pensamiento de Chicago en el ethos modernizador y su especial impacto en América Latina son bien conocidos, creo que no se ha reparado con la suficiente atención en el hecho de que prácticamente todo el pensamiento urbano latinoamericano en el período que corre entre la Segunda Guerra y los años setenta -en rigor, el único período en que existió un pensamiento urbano que podamos Ilamar «latinoamericano»se desenvolvió en el marco puesto por un debate antropológico suscitado en el interior de la problemática chicaguiana-es decir, las peripecias de los procesos de adaptación/aculturación en un mundo en transición. Me refiero al debate entre el «continuo folk-urbano» de Redfield y la «cultura de la pobreza» de Oscar Lewis. Y como el pensamiento urbano de ese período tuvo una sobredeterminación política y cultural evidente, dada la acuciante actualidad de las incógnitas de todo tipo que estaba planteando la transformación acelerada de las ciudades del continente, al compás de un desplazamiento migratorio que estaba invirtiendo ya definitivamente su tradicional carácter rural, revisar la conexión con aquel debate antropológico no supone solamente el análisis de un caso entre otros de circulación de las ideas científicas, sino la posibilidad de entrever, a través de la antropología, el espectro de figuraciones dentro del cual se movió entonces el pensamiento sobre la «ciudad latinoamericana», figuraciones que se traducían también en políticas muy activas en la reconfiguración del mismo objeto que se buscaba conocer. ${ }^{4}$

2. Robert Redfield es una figura singular dentro del nutrido contingente de scholars norteamericanos que en el último siglo y medio desarrollaron su carrera (o parte de ella) investigando en América Latina. En principio, porque es una figura que trabaja en el filo de dos épocas en relación al interés que despertaba el subcontinente: comienza sus trabajos de investigación en la década de 1920 a la búsqueda del «mundo primitivo» que ya venía caracterizando la atracción de la antropología y la arqueología por regiones como México, pero se hace una serie de preguntas que conecta claramente con las preocupaciones de posguerra sobre el desarrollo, en las que América Latina comienza a jugar el rol inverso, de tierra de promisión para el ensayo de un cambio modernizador. ${ }^{5}$ En segundo lugar, porque, de manera típicamente chicaguiana, su trabajo antropológico entabla un diálogo muy estrecho con las teorías socio-urbanas que estaban elaborándose en ese mismo momento, y ofrece un modelo de gran capacidad de síntesis y expresión (y es probable que esta suma de características haya contribuido a darle a las posiciones de Redfield una relevancia mayor de la que hubieran merecido por sus propiedades intrínsecamente teóricas).

Su interés por América Latina, especialmente por México, es, en cambio, menos singular: pura fascinación romántica, fogoneada en su caso por un viaje inaugural a través del México revolucionado de la década del veinte, donde conoció al antropólogo Manuel Gamio y definió su nueva vocación. ${ }^{6}$ En efecto, su dedicación a la antropología surgió de la combinación fortuita del conocimiento de México y su proximidad a Robert Park (con cuya hija se había casado en 1920), que entonces ya era director del Departamento de Sociología y, apenas regresó Redfield a Chicago, lo estimuló a seguir el posgrado en antropología que se dictaba allí. Así que en 1926 Redfield vuelve a México pero ya como antropólogo, a realizar en Tepoztlán, un poblado de larga tradición ubicado en la meseta central a unos 100 kilómetros al sur de la Capital, su primer estudio etnográfico que en 1930 se publica como Tepoztlan, a Mexican Village. $^{7}$

Lo que Redfield encontró en Tepoztlán fue una sociedad armónica, integrada y estable, aunque no «primitiva» sino «folk»: un grupo popularaldeano que no estaba ya aislado, pero que seguía manteniendo una serie de características socioculturales específicas del mundo tradicional tamaño reducido, status fijo, centralidad de la familia en la reproducción cultural, organización sagrada de la vida, ausencia de criterios de racionalidad instrumental, etc., etc.-, en un todo de acuerdo con el núcleo definitorio del polo comunitario-tradicional que el pensamiento social europeo había organizado en oposición al polo societario-moderno. ${ }^{8}$ Es bien conocido que ese juego de dicotomías, forjado ante el estrépito del colapso del viejo orden en la Europa de las «dos revoluciones», fue más que una forma mentis coyuntural, ya que constituyó, en términos de Nisbet (1996: 19), «la verdadera urdimbre de la tradición sociológica», hilando nombres como los de Maine, Tönnies, Weber, Durkheim y Simmel, y que en los Estados Unidos no sólo ingresó a través de la lectura y el contacto con los autores europeos, sino que encarnó en categorías propias, muy influyentes en la formación de la escuela de 
Chicago, como los «folkways» de William G. Sumner, o la diferenciación de Charles H. Cooley entre «grupos primarios» $y$ «secundarios».

Luego de ese primer trabajo etnográfico, Redfield se instaló en el área cultural maya, entre la península de Yucatán y Guatemala, y se propuso estudiar diversas comunidades para desarrollar su propia tipología dicotómica: la polaridad «folkurbana», que plasmó en el libro The Folk Culture of Yucatan, de 1941, y en un famoso artículo, «The Folk Society», de 1947. Pese a que en ambos títulos figura exclusivamente el polo «folk» del par dicotómico, esa investigación fue uno de los intentos más ambiciosos por comprender el cambio social y cultural en el pasaje de la comunidad aldeana a la sociedad urbana; como el mismo Redfield lo definió en el prólogo a The Folk Culture of Yucatan, el intento de poner a prueba etnográficamente las dicotomías teóricas clásicas y formular a partir de allí una tipología ajustada a ese pasaje civilizatorio -por eso, la traducción al castellano del libro lleva un título mucho más coherente con el núcleo problemático de la empresa de conocimiento redfieldiana: Yucatán: una cultura en transición. Redfield construyó en esa investigación el «continuo folk-urbano» como en un experimento de laboratorio: seleccionó cuatro comunidades de la región situadas en diferente posición en la línea imaginaria que va de la menor a la mayor urbanidad (de una comunidad tribal en Quintana Roo a la sociedad urbana de Mérida), organizando su análisis como una línea «evolutiva» caracterizada por la diferente intensidad del contacto con el polo civilizador, y buscó determinar los rasgos de esas comunidades que iban siendo afectados en tal contacto. Así, postuló que los pares polares aislamientohomogeneidad / comunicación-heterogeneidad constituían, dentro de un conjunto de variables interdependientes, la polaridad dominante, porque de ella dependían otras, como organización / desorganización de la cultura; sacralidad / secularización; colectivismo / individualismo. Era como asistir, en una pequeña porción del territorio americano, al cuadro vivo de la completa civilización humana, ya que para Redfield (1947: 306) «todos los hombres vivieron en un tiempo en esas pequeñas sociedades folk», y todos se encaminan hacia esa otra forma, tan reciente y novedosa -si se considera «la larga historia del hombre sobre la tierra»-, que es la sociedad urbana.

Por supuesto, como todas las críticas advirtieron en su tiempo, este extremo moderno del continuo, la ciudad, no recibía de parte de Redfield ningún análisis específico, sino que respondía punto a punto a la definición que unos años atrás había estilizado Louis Wirth (1938) en uno de los textos más famosos de Chicago: «Urbanism as a Way of Life». Cuando se revisan juntos los dos artículos -el «paradigma Wirth-
Redfield», como se lo consideró desde entoncessorprenden básicamente la claridad y la elegancia con que ambos autores supieron organizar y condensar (en 24 y 16 páginas del Journal respectivamente) toda una tradición de pensamiento sobre las formas sociales opuestas del par tradición/modernidad, siendo posiblemente quienes tuvieron mayor capacidad para extender los puntos de vista de la sociología urbana de Chicago, aún al riesgo de su simplificación: si con la idea de «urbanismo como forma de vida», Wirth popularizó toda la compleja visión culturalista sobre la ciudad (de Simmel a Park), la fórmula del "continuo folk-urbano» interesaría decisivamente el enfoque funcionalista de la planificación para el desarrollo. Por esto mismo, sorprende también que el paradigma más influyente en el pensamiento urbano de una disciplina tan positiva y optimista como la planificación, estuviera sostenido en una radical ambigüedad respecto de cualquier idea de «progreso» implícita en esa «evolución», ya que en ambos autores también sobrevivían la idealización del orden y la estabilidad del polo folk y el recelo sobre su inevitable inversión en el polo urbano que caracterizaron a toda la reflexión clásica sobre la modernidad. ¿Cómo fue digerida esa ambigüedad en el pensamiento planificador? $\mathrm{O}$, mejor, ¿qué marcas dejó? Sobre esto vamos a volver.

3. En 1943, apenas dos años después de la publicación de The Folk Culture of Yucatan, Oscar Lewis, recién graduado de antropólogo en la Universidad de Columbia, decide comenzar su carrera de investigador "reestudiando» la población en la que Redfield había iniciado la suya, Tepoztlán; una decisión casi estética de rebatir el paradigma en su mismo terreno de origen, que dio lugar a un debate clásico en etnología interpretativa (según la valoración de Hannerz, 1986: 85) y convirtió a Tepoztlán en un santuario de la historia de la antropología. ${ }^{9}$

Muy poco después de su llegada, Lewis ya publicaba un artículo en el que mostraba los cambios modernizadores en Tepoztlán en el período transcurrido desde la estadía de Redfield, derivados de la urbanización del país -que crecía imparable desde 1940, con el efecto principal de la atracción de la ciudad capital sobre poblaciones como la de Tepoztlán-y de su «americanización» -alimentada no sólo por la expansión económica y cultural norteamericana de posguerra, sino también por la masificación de la figura del «brasero» (Lewis, 1944); en 1951 publicó el estudio completo como libro: Life in a Mexican Village: Tepoztlan Reestudied. Lewis buscó allí reemplazar el formalismo de los análisis culturales de Redfield con la inclusión de aproximaciones a la psicología y la historia de la comunidad (que fueron muy criticadas a la vez por su 
esquematismo), con la finalidad de probar que los tepoztecos no eran la comunidad armónica y estable que había descripto Redfield y, especialmente, que sus cambios culturales no provenían con exclusividad de una fuente «civilizatoria» externa, como se desprendía del esquema folk-urbano, sino de heterogeneidades histórico-culturales propias.

Pero su búsqueda de rebatir a Redfield apenas comenzaba. El paso decisivo fue una puesta a prueba del propio «continuo» en una investigación que se organizó también a través de un esquema de seguimiento del proceso de «transición», pero ya no como en el estudio sobre Yucatán en el que Redfield había seleccionado cuatro estadios, como cuatro fotografías tomadas sobre la línea imaginaria que va de lo folk a lo urbano, sino siguiendo la dinámica del pasaje, a través de dos familias que encarnaban, en su propia experiencia migratoria de Tepoztlán a una vecindad de la ciudad de México, el «contacto aculturador». ${ }^{10}$ Con los primeros resultados, Lewis (1952) publicó «Urbanization without Breakdown: a Case Study», un artículo en el que propuso a la familia como unidad de análisis antropológico pertinente, dando toda una definición metodológica respecto de las pervivencias de lo tradicional en lo moderno. Manteniéndose fiel a las modificaciones de un objeto de estudio que se desplaza, como un documentalista que se propusiera registrar paso a paso las peripecias de una mudanza familiar, el antropólogo llega a la ciudad o, con mayor precisión, a sus intersticios degradados, los sitios donde los migrantes debían afrontar la prueba definitiva en su proceso de adaptación a la vida metropolitana. El estudio muestra los primeros resultados de un trabajo de relevamiento y análisis de la vida de 100 familias tepoztecas en ciudad de México que reúne, por primera vez en América Latina, la indagación sobre las causas de la migración en el punto de origen y sobre las razones de la atracción en el punto de llegada, y formula hipótesis sobre el impacto psico-social y cultural de la mudanza. Y, vale la pena insistir, lo hace en el mismo momento en que la migración ruralurbana se está convirtiendo en la cuestión sociológica, política y cultural capital en América Latina.

A partir de esa investigación, Lewis definió la vecindad como el locus privilegiado para el análisis de la cultura migrante y amplió su espectro de casos al de otras comunidades de origen, publicando en 1959 Five Families (Mexican Case Study in the Culture of Poverty), el libro en el que narró la experiencia de cinco familias, dos de las tepoztecas que ya había estudiado y otras tres provenientes de diferentes regiones (Lewis, 1959a). Aquí presentó por primera vez la categoría que lo haría famoso, «cultura de la pobreza», a la que dedicó apenas unos párrafos en la introducción, y, especialmente, inició el estilo de relato que se convertiría en su marca reconocible, al que llamó «realismo etnográfico» («no es ficción ni antropología convencional»): una reconstrucción cuasi novelada de los testimonios recogidos en forma de biografía colectiva, utilizando procedimientos característicos de la ficción -en este caso, el relato de «un día en la vida» de cada familia. $Y$ es significativo que Lewis inicie desde la antropología un movimiento simétrico al que se estaba iniciando, en esos mismos momentos, desde la literatura hacia la non-fiction (como se recuerda, Rodolfo Walsh publicó Operación masacre en 1957, y el mismo 1959 fue el crimen que llevaría a Truman Capote a publicar, en 1966, el libro más famoso del género, $A$ sangre fría): el antropólogo se aleja de la ciencia y los escritores de la ficción para encontrarse en un punto medio de difícil definición, especialmente para los cánones de la primera.

En todo este ciclo de su debate con Redfield, Lewis buscó probar, básicamente, que el proceso de urbanización social no es ni unitario ni universal, sino que depende de las condiciones de partida -históricas, económicas, sociales y culturales- de cada grupo migrante (cfr. Lewis, 1952: 39-41). Y en términos más específicos, que no había podido reconocer en la ciudad casi ninguno de los factores clásicos «del enfoque Simmel-Wirth-Redfield» (como él mismo lo llama): ni anonimato personal, ni aislamiento individual, ni desorganización social, más bien lo contrario, ya que verificó la reproducción de los lazos fuertes de la familia ampliada y el espíritu comunitario que se extiende a todos los que comparten la misma procedencia; tampoco secularización, ya que la vida religiosa siguió siendo vigorosa en la ciudad -y aún más, por la mejor organización que ofrece allí la Iglesia católica-; ni abandono de rasgos culturales elementales, como son la alimentación o las prácticas de curación tradicionales. En su síntesis crítica a aquel paradigma, finalmente, sostuvo que no había llegado a encontrar «evidencias experimentales $u$ otras válidas que indiquen que la exposición de un gran número de personas por este sólo hecho las lleve a la ansiedad o a la tensión nerviosa o que la existencia de las relaciones secundarias disminuya la fuerza e importancia de las relaciones primarias» (Lewis, 1965: 497). Es decir, la ciudad no es sólo ese mundo heterogéneo e impersonal que recibe al migrante como un mero individuo que debe adaptarse a condiciones completamente ajenas a su experiencia, ya que el fenómeno migratorio ha formado en ella «pequeñas comunidades»-tal su definición de vecindad-que actúan en forma cohesiva y «amortiguan» el impacto de la mudanza al recrear, en el nuevo medio urbano, un universo cultural completamente semejante al de la procedencia. ${ }^{11}$

Es sencillo comprender que estos argumentos 
importaban muy directamente cuestiones candentes del debate latinoamericano: ¿cómo comprender a los migrantes?, ¿qué hacer con ellos?, ¿cómo integrarlos al proceso de modernización que la ciudad debería encarnar frente a su origen rural? Y, especialmente, ¿qué hacer con sus lugares de residencia idiosincráticos, que ya no eran tanto las vecindades, sino las villas miseria, las favelas, las barriadas, las poblaciones callampa, esos campamentos provisorios cuya proliferación morbosa le estaba dando su marca definitiva a la "ciudad latinoamericana»? ${ }^{12}$ En la segunda mitad de la década de 1950 este tipo de preguntas comenzaba a organizar la agenda de problemas de las nacientes ciencias sociales en el continente, en diálogo directo con las teorías norteamericanas y con la producción de los investigadores de ese origen en la región. En 1959, el año de publicación de Five Families, Lewis presentó su trabajo sobre "la cultura de la vecindad» (una especie de compendio de sus conclusiones respecto del hábitat de la cultura de la pobreza en la ciudad de México) en el «Seminario sobre problemas de urbanización en América Latina», organizado en Santiago de Chile por CEPAL y UNESCO, en el que se relataron los resultados de los primeros estudios sociológicos sistemáticos realizados en poblaciones urbanas marginales con intención comparativa, los que con el patrocinio de UNESCO y la guía de Philip Hauser llevaron adelante José Matos Mar en Lima, Andrew Pearse en Río de Janeiro y Gino Germani en Buenos Aires (cfr. Hauser, 1967).

4. Pero antes de abordar este contacto entre el debate antropológico y los estudios sociales latinoamericanos, conviene puntualizar un par de cuestiones sobre el debate mismo. Se mencionó al inicio que debía considerárselo como interno a la problemática chicaguiana, y esto es importante aclararlo porque en las lecturas que recibió ya entrada la década de 1960, se produjo un deslizamiento de sentido por el cual las críticas de Lewis al modelo folk-urbano quedaron fijadas sin más como desmentidos radicales del conjunto de supuestos de la socio-antropología urbana de Chicago. Sin embargo, en los textos de Lewis de este primer período es muy evidente que toda la argumentación de la «cultura de la pobreza» está orientada a ofrecer herramientas para favorecer una buena asimilación de los migrantes; es decir que, paradójicamente, Lewis radicaliza a su manera la idea de «continuo», como bien señala su fórmula «urbanization without breakdown». Porque si bien se ocupa de mostrar que ni el extremo folk es como lo tipologiza Redfield, ni el extremo urbano como lo hace Wirth (al menos no en la ciudad latinoamericana, ya que lo que cuestiona Lewis de las definiciones simmelwirthianas sobre la "cultura urbana» es su voluntad universalista, no su capacidad de caracterizar acertadamente a la ciudad altamente industrializada de Europa o Norteamérica), en ningún momento se aparta de la problemática misma de la «transición». Los objetivos reformistas de Chicago de comprender las leyes del cambio social para favorecer la mejor integración de lo tradicional en lo moderno, no están puestos nunca en duda; en todo caso, lo que Lewis le señala a los teóricos y, muy especialmente, a los planificadores funcionalistas es que para cumplir adecuadamente con ellos se debe tomar en cuenta muy en serio el camino que los propios migrantes muestran en su laboriosa empresa de integración a la vida urbana, una especie de «ajuste funcional» al nuevo medio, en el que la eficacia está dada por el uso acertado de los propios recursos culturales «tradicionales», que no deben ser tomados entonces como rémoras que dificultan la «aculturación». Ésta, en definitiva, entendida como pérdida de la propia cultura, no sería ni necesaria ni conveniente para garantizar una adaptación exitosa a la realidad de la ciudad latinoamericana.

Por otra parte, una lectura actual de las posiciones de Lewis permite comprender hasta qué punto sintonizaban bien con buena parte de las posiciones «originarias» de Chicago, las de Robert Park, en quien la ambigüedad respecto del «proceso de civilización» está todavía más claramente presente que en las estilizaciones de Wirth y Redfield y, especialmente, que en sus usos funcionalistas. Como señalaron ya hace tiempo Morton y Lucía White en un libro clásico, El intelectual contra la ciudad, Park pensaba que «los inmigrantes recientemente llegados, quienes mantenían sus sencillos hábitos aldeanos con organizaciones religiosas y de ayuda mutua, habían conseguido resistir mejor el impacto del nuevo medio ambiente» (White, 1967: 159). Visto desde este ángulo, el debate entre Lewis y Redfield se desplaza: no es sólo sobre cómo mejorar la adaptación, sino sobre qué rol tienen los «otros», los aldeanos, en la cultura urbana. La respuesta de Park al respecto no habría dejado lugar a dudas: un rol moralizador.

En el texto fundacional de la temática urbana en Chicago, «La ciudad. Sugerencias para la investigación del comportamiento humano en el medio urbano», el artículo de Park de 1915 que luego abrió The City (1925), ya se usaba la definición de «sociedad primitiva» de Sumner para caracterizar el funcionamiento de los grupos primarios que persistían dentro de la gran ciudad, en ese caso, las redes caudillescas de la política municipal que «forman un 'nosotros', mientras el resto de la ciudad es sólo el mundo exterior, que no es tan animado ni tan humano como los miembros del 'nosotros'». ${ }^{13}$ Pero si en este ejemplo la corrupción de esas redes políticas orientaba negativamente el juicio sobre tal pervivencia «de naturaleza completamente feudal», en un artículo 
de 1925, que también integró The City, Park va a plantear a la comunidad de inmigrantes como un «modelo» para la sociedad urbana norteamericana, en la búsqueda de alentar "un nuevo espíritu aldeano». ${ }^{14}$ Ya que, como sostiene en «La ciudad como laboratorio social» de 1929, el problema social de la metrópoli es el de lograr «en la libertad de la ciudad, un orden social y un control social equivalentes a eso que crece de forma natural en la familia, en el clan y en la tribu» (Park, 1999: 115). En esta reivindicación del rol preservador de los grupos primarios dentro de la ciudad, articulada con una definición reformista del cambio social que les abre posibilidades de adaptación, se ve la preponderancia de la matriz durkheimiana -el intento de mostrar que la sociedad moderna sólo podrá afianzarse si se apoya en aspectos sensibles de la sociedad tradicional, no en su negación completa- y la doble diferencia que establece el pensamiento de Chicago frente a otras influencias muy importantes: por una parte, frente a la posición más radicalmente modernista de Simmel; por la otra, frente al darwinismo conservador de una figura como Sumner. ${ }^{15}$ No es difícil entender que las aportaciones de Lewis pudieran ser leídas en el andarivel de ese mismo equilibrio reformista respecto del rol de la comunidad en la sociedad.

5. El debate latinoamericano interpretó con sus propias claves esa tradición reformista y los textos de Lewis ingresaron en los años cincuenta en todo caso como un correctivo para pensar los procesos de transición locales o, mejor, como una primera traducción: la importancia que se le daba en Chicago a la aldea, el ghetto o el barrio, en Lewis aparecía ya bajo una forma típicamente latinoamericana, la vecindad, desde la que resultaba muy fácil hacer el pasaje a ese otro dispositivo urbano en el que iba a tomar forma la «otredad» aldeana en las ciudades latinoamericanas contemporáneas hasta mimetizarse con ella: la villa miseria.

Es ilustrativo, en este sentido, el estado del debate latinoamericano sobre esa cuestión crucial. La villa miseria era el diafragma delicado que materializaba el momento más dramático de la transición, donde la cualidad temporal que parecía dar cuenta acabada de la percepción teórica sobre ella, quedaba fijada en espacios inaceptables para la percepción tanto política como urbana. El seminario de 1959 en Santiago nos ofrece un buen panorama del estado de la investigación sobre esos temas, que muy poco tiempo atrás habían comenzado a recibir la atención analítica de las nacientes ciencias sociales. Es importante detenerse en esa fuente, producida en el momento de apogeo del debate Redfield/Lewis, porque se trata de un tema que rápidamente iba a entrar en un ciclo de enormes mutaciones, tanto en la opinión científica como política. Como anticipamos, los casos que recibieron una atención sistemática en el seminario de 1959 fueron tres: Lima, Río de Janeiro y Buenos Aires, constituyendo una de las secciones principales del seminario. ${ }^{16}$

El relator del caso de Lima fue José Matos Mar, antropólogo social del Instituto de Etnología de la Universidad de San Marcos, que presentó los estudios sobre las barriadas que venía realizando junto al geógrafo británico John P. Cole, iniciados en 1955 por encargo de la UNESCO. ${ }^{17}$ Matos Mar formaba parte del círculo reformista de una figura muy particular de la política peruana del período, el arquitecto Fernando Belaúnde Terry, quien ya había impulsado como diputado la creación de la Corporación Nacional de la Vivienda en 1945, a lo que le siguió una serie de iniciativas institucionales muy características del ethos planificador de la época (Instituto Nacional de Urbanismo, Oficina Nacional de Planeamiento y Urbanismo) que fueron amojonando su llegada a la presidencia de la nación en 1963 con el partido Acción Popular, encarnando de un modo ciertamente emblemático la centralidad que en esos años asumieron los problemas del desarrollo urbano en la agenda política de los países latinoamericanos. ${ }^{18}$

En su estudio de 1959, Matos Mar presentaba las barriadas no como un problema «de vivienda» -que era el modo en que lo venía abordando el pensamiento urbano modernista dominado por la ideología arquitectónica-, sino como un «reflejo del desequilibrio en las estructuras económicas y sociales nacionales» que estaba produciendo la vertiginosa migración de la población rural mayoritariamente de la región andina-, a través de un proceso escalonado que finalmente conducía a Lima. Por esa razón, entre 1940 y 1957 la población limeña se había triplicado (llegando a 1.370 .000 habitantes), concentrando el $50 \%$ de la población urbana nacional y configurando uno de los casos extremos de un fenómeno típicamente latinoamericano: la alta «primacía» urbana -la segunda ciudad del país, Arequipa, no llegaba al $10 \%$ de la población limeña (1 17.000 habitantes) (Matos Mar, 1967: 193). Pero el fenómeno más notable radicaba en que buena parte de ese crecimiento se producía en las barriadas limeñas, cuya población también ya había superado a la de Arequipa, en un ritmo mucho más elevado que el ya elevado de la propia capital. ${ }^{19}$

El estudio de Matos Mar mostraba cómo la falta de desarrollo y oportunidades en el interior estaba acompañando un proceso de «urbanización cultural» de todo el país, en el que sobresalían los efectos dislocadores de unos medios de comunicación y un sistema educativo de concepción unitaria sobre una población culturalmente heterogénea, de modo que los estímulos que creaban en su extensión nacional sólo podían encontrar efectiva respuesta en la capital. Con un resultado doble: la emergencia de 
una clase mestiza nacional, con «valores y modalidades propias de formas de vida urbana», y el surgimiento en la ciudad de núcleos importantes de cultura rural con patrones tradicionales, especialmente de matriz indígena serrana, que sufren «desajustes mentales, sociales y económicos que atentan contra su buena adaptación» (Matos Mar, 1967: 196).

Pero si esos términos parecen reproducir la concepción funcionalista de la «desorganización social» en el continuo folk-urbano, rápidamente Matos Mar se ocupa de describir, en términos completamente análogos a los de la corrección lewisiana del paradigma, los recursos culturales y las tramas organizacionales de los grupos migrantes que funcionan como «mecanismos de compensación», el principal de ellos, como en el caso de la vecindad mexicana, la familia. Así, las barriadas «repiten en su estructura tradicionales sistemas comunitarios» de organización cooperativista -en los que, por ejemplo, se eligen autoridades por un sistema de representación familiar, que si parece tradicional, Matos Mar sugiere que es, en verdad, con su carácter electivo y público, mucho más democrático que el sistema de designación directa de las autoridades municipales usual en Perú-, caracterizados por un conjunto de hábitos, desde los patrones habitacionales hasta la medicina, la alimentación y el sistema de «creencias mágicorreligiosas», por no mencionar la propia lengua «extranjera», constituyendo una intrusión popular-tradicionalaldeana en la vida metropolitana. Podría decirse que en Matos Mar conviven la preocupación por mostrar la integración efectiva de la población de las barriadas a la vida económica de la ciudad (contra los tradicionales estigmas de marginalidad, muestra que casi el $60 \%$ de los pobladores de las barriadas son obreros y que casi el $90 \%$ trabaja fuera del barrio) y la sensibilidad por identificar, en su aislamiento cultural, la importancia de los roles amortiguadores de una identidad indígena-comunitaria desdeñada por la cultura criolla dominante.

El caso de Río de Janeiro fue presentado por Andrew Pearse, un antropólogo y sociólogo inglés que, como experto de la UNESCO con sede en el Centro Brasileiro de Pesquisas Educacionais (CBPE), había realizado entre 1956 y 1957 un estudio sobre la integración de la población favelada a través de la escuela (Pearse, 1958). ${ }^{20}$ En su relato en el Seminario, Pearse dio definiciones generales sobre la favela bastante coincidentes con las de Matos Mar sobre las barriadas: la consideró una consecuencia de las desigualdades en la estructura socioeconómica del Brasil, un dispositivo urbano que «desempeña una función inevitable y esencial en la relación entre el sector urbano rico e industrial y el sector rural pobre y agrícola, que se encuentran separados por una excepcional laguna económica» (Pearse, 1967: 220). Además de su estudio cualitativo, se apoyó en análisis censales que indicaban que la población favelada ya alcanzaba en 1957 un 30\% de la población de Río (650.000 sobre 2 millones de habitantes), cifra que coincidía con la que circulaba desde años atrás en la opinión pública, pero que había sido desmentida por los primeros censos específicos de 1948 y 1950, que daban una población favelada menor al 10\%. ${ }^{21}$

La polémica cuantitativa, habitual en estos temas controvertidos y de difícil mensura (no sólo por las condiciones de implantación de los asentamientos, sino porque la propia definición de lo que debía o no ser considerado una favela en términos censales estaba en discusión), en el caso de Río es también un indicio de la existencia más temprana de estudios sobre el tema: posiblemente porque se trataba de un fenómeno de más larga data, ya que las primeras ocupaciones ilegales de morros en Río de Janeiro se habían realizado a finales del siglo XIX, tanto el debate político-social como los trabajos de relevamiento e investigación de las favelas habían desarrollado en Brasil un campo de reflexión específica más denso y variado. ${ }^{22}$

De hecho, Pearse estaba en contacto en el CBPE con Luiz Costa Pintos, una de las principales figuras en la renovación de las ciencias sociales en Brasil, que había dedicado a la favela uno de los capítulos de su libro de 1953 O negro no Rio de Janeiro, resultado de una investigación sobre las relaciones raciales también financiado por la UNESCO. ${ }^{23}$ Y casi en el mismo momento en que Pearse hacía su trabajo de campo, se estaba llevando adelante un estudio integral de las favelas de Río a cargo de la Sociedade de Analise Gráfica e Mecanográfica Aplicada aos Complexos Sociais (SAGMACS), el equipo técnico formado una década atrás en San Pablo por Louis-Joseph Lebret, el sacerdote francés que había creado en Bretaña el movimiento Économie et Humanisme, referente internacional de los movimientos de renovación católica en la posguerra, con especial énfasis en la planificación humanista. ${ }^{24} \mathrm{Y}$ este es un caso especialmente representativo tanto de la pluralidad de los abordajes científicos que en Brasil ya generaba la cuestión de la favela, como de sus enormes repercusiones políticas y culturales: SAGMACS había sido convocada a Río de Janeiro por el obispo Helder Cámara, que en 1955 había impulsado la Cruzada São Sebastião a favor de una acción integral para la urbanización de la favela equipamiento, infraestructura y vivienda por sistemas de autoayuda-, radicalizando su defensa como comunidad frente a las campañas políticas que pedían su erradicación. ${ }^{25}$

Retomando la presentación de Pearse, ésta también coincide con la de Matos Mar en definir a la favela como una «intrusión de viviendas de tipo rural en el sistema urbano de vida» (Pearse, 1967: 220). Pero esa separación ambiental (reflejo de la 
separación radical en los patrones socioeconómicos de la población campesina) no encuentra en la favela el correlato dual que, en términos socio-culturales, parece caracterizar a la barriada limeña por la proveniencia indígena de su población. Porque si bien es cierto que, para Pearse, los habitantes de la favela son ajenos a la experiencia urbana y encuentran grandes dificultades para integrarse a ella, también es indudable que los ve como parte de una cultura moderna popular-nacional mucho más integrada que en Perú.

Así señala, por una parte, las características «tradicionales» de la población favelada que explican su «desorganización» a través de índices característicos de la indagación funcionalista: la baja sindicalización, las dificultades para incorporar los hábitos laborales de las grandes empresas, el bajo «sentimiento de barrio», el bajo nivel de asociacionismo como contratara de un fuerte familiarismo -aunque subraya la paradoja de que la familia nuclear migrante es más «moderna» que la familia ampliada todavía habitual tanto en las clases altas rurales como urbanasque se extiende en la trama de los «grupos de parentela», formando una cadena migratoria «en movimiento constante hacia la ciudad» (Pearse, 1967: 224). Pero, por la otra parte, aparece claro en su texto que los favelados encuentran una integración principal a través de la cultura de masas a la que ya pertenecen (el futbol, la quiniela, la radio), al punto de que es ese contraste entre ciertos hábitos «tradicionales» y la forma de vida urbana moderna lo que le permite a Pearse explicar el populismo brasileño como un reemplazo de la vieja dependencia personal del mundo rural por nuevos tipos de protección estatal en el contexto de una cultura masiva del bienestar, una característica política que está muy lejos de circunscribirse a la favela.

A diferencia de la combinación limeña entre integración funcional y separación cultural, Pearse está menos interesado en probar las formas de integración económica que en analizar la plasticidad de la adaptación socio-cultural a una tradición política de populismo. La favela no es para él tanto una «puerta de entrada» a la ciudad, como el sitio marginado desde el cual el migrante se ve obligado a adaptarse a ella, configurando una nueva forma moderna de la desventaja socioeconómica. Y en este sentido sus hipótesis son bastante coincidentes con las que estaba elaborando contemporáneamente el estudio de la SAGMACS, que si bien defiende la favela como comunidad, no lo hace en función de alguna esencia cultural de origen ni de un carácter presuntamente marginal a la sociedad urbana, sino de sus logros en establecerse en un medio adverso. 26

El caso de Buenos Aires, por su parte, fue relatado en el seminario de Santiago de Chile por
Gino Germani, a quien el encargo de la UNESCO lo había llevado a realizar su primera incursión en temas urbanos que fue, al mismo tiempo, el primer estudio sobre la ciudad con los instrumentos de la sociología «científica»-un doble bautismo para una articulación clásica. ${ }^{27}$ Germani eligió para hacerlo la Isla Maciel, un fragmento tradicional del área industrial de Avellaneda, porque el Departamento de Extensión de la Universidad de Buenos Aires había instalado allí un centro de acción social que necesitaba una encuesta y que, a su vez, servía al equipo de sociólogos como carta de presentación ante habitantes especialmente recelosos frente a las instituciones públicas desde la caída del gobierno del presidente Perón. ${ }^{28}$ Pero, además, el sector ofrecía una posibilidad en completa sintonía con nuestro problema: la existencia en el área circunscripta de la Isla de un «continuo» de urbanización, desde un sector de villa miseria reciente, hasta un sector popular de edificación regular y asentamiento arraigado en la zona, lo que llevó a Germani a organizar su investigación a través de cinco grupos poblacionales de estudio que (como las cuatro comunidades yucatecas de Redfield, pero en una geografía mucho más concentrada) le permitían analizar diferentes estadios de la transición folkurbana: «una especie de progresión desde las familias inmigradas más homogéneas en cuanto a origen de sus miembros y carácter reciente de su inmigración, hasta las familias totalmente nativas» (Germani, 1967: 235).

Es notorio que Germani presenta sus resultados sobre el fondo implícito del paradigma Wirth-Redfield, con un tipo de argumentación que busca verificar en qué se cumple y en qué no el continuo transicional, para hacer los ajustes empíricos adecuados al caso de Buenos Aires. Así, ve cumplirse casi redfieldianamente un proceso en el cual la mayor integración supone transformaciones progresivas en los cinco grupos hacia las pautas del matrimonio legal, una menor cantidad de hijos, relaciones familiares más abiertas e igualitarias, un mayor grado de asociacionismo, un mayor nivel ocupacional (sobre una base de plena ocupación, la progresión va de las actividades de servicio a las industriales), un mayor nivel educativo. ${ }^{29}$ También es sensible a esa preocupación típicamente chicaguiana, que es descubrir que «el barrio tiende a heredar transformadas y dentro del cuadro de la metrópoliparte de las funciones de las pequeñas comunidades de la sociedad tradicional, manteniendo incluso ciertos sentimientos de identificación y pertenencia que son bastante perceptibles en la zona urbanizada de la isla» (Germani, 1967: 253). Y, ya en completa sintonía con el «ajuste» lewisiano, tiene que reconocer que le resulta muy difícil la utilización de la dicotomía clásica de «organización/desorganización» atribuida al mundo tradicional y al moderno 
respectivamente. Ya que así como, por una parte, no es posible encontrar en el origen de los grupos migrantes una diferencia sustancial en cuanto a la estabilidad o cohesión familiar y comunitaria lo que indica una gran homogeneidad de partida en las pautas socio-culturales de migrantes y nativos de la ciudad, debido a la temprana extensión nacional de los rasgos característicos de una sociedad altamente urbanizada (y debido también a que, por esa misma causa, sólo muy pocos migrantes llegan directamente de áreas rurales, siendo lo normal un proceso de migración escalonado desde ciudades pequeñas a medianas que conduce finalmente a Buenos Aires)-, por otra parte, son mayores los rasgos de «desorganización» en los sitios de partida de la población popular no urbana que en la propia ciudad, con lo cual el proceso de urbanización «produce a la vez -y algo paradójicamenteorganización y desorganización» (Germani, 1967: 242). Es decir que Germani encuentra en el proceso migratorio de Buenos Aires un continuo muy acortado, lo que supone reconocer que ni el polo folk ni el urbano pueden identificarse con la claridad de las tipologías clásicas.

Analizando de conjunto los tres relatos, es fácil ver que comparten la preocupación por demostrar la integración socio-económica en las actividades urbanas de las poblaciones estigmatizadas como «marginales» (como se señala conclusivamente en uno de los capítulos programáticos del libro de la UNESCO: Ios migrantes «no constituyen un grupo que se distinga claramente de las clases urbanas inferiores en general»), asumiendo una especie de dualismo atenuado o reformista, en el que se intenta precisar las desventajas diversas de partida de los grupos migrantes (más sociales, o económicas, o culturales, según el caso), bajo un prisma que valora la integración a los sectores modernos identificados con la cultura urbana. ${ }^{30}$ Es notable que los tres forman parte de un primer estadio de revisión de las nociones más crasamente funcionalistas, ante la evidencia de que algunos de sus postulados teóricos condenaban la realidad de la urbanización latinoamericana al lugar de la patología. En el caso de las migraciones, esto se verifica en la continua advertencia sobre los límites de nociones como «sobreurbanización» o de la misma dicotomía «tradicional/moderno»; no porque estos analistas no participaran de la visión crítica sobre los procesos que conducían a esos fenómenos (como el desfasaje entre las tasas de urbanización y las de industrialización, o el peso de las migraciones en la extensión de un sector de servicios de bajísimo standard), sino porque advertían que, colocados en aquellos moldes teóricos, esas nociones terminaban caracterizando a la ciudad latinoamericana como mera desviación de la norma dictada por la modernización occidental.

Finalmente, los tres análisis de Lima, Río y
Buenos Aires podrían leerse de corrido también como una ejemplificación de los diferentes momentos del continuo folk-urbano en una escala continental, desde la mayor contraposición entre migrantes rurales y habitantes urbanos en Lima, hasta la mayor cercanía entre los dos polos en Buenos Aires, como las estaciones progresivas de un único estudio de transición de lo tradicional a lo moderno, suficientemente poroso como para incorporar en variadas proporciones los ingredientes diversos de un funcionalismo à la Refield o un culturalismo à la Lewis. ${ }^{31}$ Es claro que el main stream de las nacientes ciencias sociales en la región se movía, en 1959, dentro de la noción de «continuo», viendo en ella un instrumento pasible de ajustes que permitirían incorporar la peculiaridad latinoamericana de sociedades en tránsito a diversas formas de integración urbana, tanto porque cada una partía de polos tradicionales completamente diversos, como porque la propia consistencia moderna del polo urbano debía entenderse idiosincrásicamente en cada caso.

6. «Dualismo» $\mathrm{y}$ «marginalidad» son palabras que, como se sabe, en 1959 estaban a las puertas de una transformación vertiginosa, como objetos de polémicas intensísimas a la luz de las cuales todavía hoy se sigue juzgando aquella producción anterior. Por eso es importante detenerse un poco más ante la frontera que en estos temas nos pone la década de 1960, para analizar los correlatos operativos de aquellas posiciones sobre el continuo transicional en las ideas sobre vivienda social. Porque, ¿dónde encontrar más claramente delineadas las posiciones sobre el rol de los «aldeanos» en la ciudad, que en los debates sobre cómo deberían ser sus casas y sus barrios?

Es notorio que, en los años cincuenta, la vieja «cuestión de la vivienda» había vuelto a convertirse en un gran disparador de la imaginación social y política en la región, produciendo un terreno aparentemente común para las indagaciones de la antropología y la sociología y las de la arquitectura; aunque ésta podía, en verdad, reclamar una notable precedencia frente a las ciencias sociales, ya que hacía por lo menos tres décadas que había activado su revolución modernista gracias a una reflexión original sobre la vivienda masiva, asentada para mediados de siglo en una respuesta formal y tipológica, la «unidad de habitación». De hecho, desde los años cuarenta había comenzado la construcción, en diversos países de la región, de una serie de grandes conjuntos habitacionales que ponían en juego los criterios más avanzados de la arquitectura internacional para la vivienda social, consolidando la alianza entre estado y arquitectura moderna por medio de la cual se venía produciendo, desde la década de 1930, una radical transformación territorial en América Latina 
(Gorelik, 2005b). Conjuntos como «El Silencio» (1941) o la urbanización «23 de Enero» (1954), ambos de Carlos Raúl Villanueva en Caracas; obras como «Pedregulho» (1950), de Affonso Reidy en Río de Janeiro, o las "Superquadras» concebidas por Lucio Costa para Brasilia (1957); los «multifamiliares» «Miguel Alemán» (1947) y «Presidente Juárez» (1950), ambos de Mario Pani en México; entre muchos otros ejemplos, fueron apenas los hitos arquitectónicos detrás de cuya enorme visibilidad se encolumnó una vastísima producción llevada adelante por instituciones públicas como el Banco Obrero de Venezuela, el Departamento de Habitação Popular de la Prefectura de Río y los Institutos de Aposedantorias e Pensões en Brasil, la Caja de Habitación Popular y la Corporación de la Vivienda en Chile, la Secretaría de Vivienda de la Municipalidad de la Ciudad de Buenos Aires y el Banco Hipotecario Nacional en la Argentina, etc., etc. ${ }^{32}$ Así se desplegó sobre las principales ciudades del continente una miríada de marcas materiales del común impulso modernizador que inspiraba a los cuerpos técnicos estatales, más allá de las notorias divergencias políticas e ideológicas entre los diversos gobiernos. Fueron, por supuesto, emblemas difusores de representaciones políticas dentro de una tradición estatal de utilización grandilocuente de la obra pública con fines propagandísticos, pero también la señal de madurez de la experimentación arquitectónica local y, especialmente, la orgullosa forma en que América Latina celebraba sus potenciales atributos para resolver sus conflictos sociales a partir de un salto adelante sobre su propia modernidad.

Es sabido que este modelo habitacional también reconoce un originario aliento comunitarista, reactivo a la disolución metropolitana de los lazos sociales primarios. Pero su idea de comunidad era mucho más un proyecto de organización colectiva adecuada a los nuevos tiempos, que una puesta en valor de especificidades culturales que debieran preservarse o siquiera aprovecharse en su capacidad «amortiguadora». En este sentido, la idea de «unidad de habitación» encuentra analogías en el universalismo de la noción de «continuo folk-urbano», proponiéndose como instrumento capaz de reparar las aristas más conflictivas de la vida metropolitana: es la respuesta modernista -tomada por un importante sector de las «vanguardias históricas»- al diagnóstico simmeliano; una respuesta que opta por radicalizar las lecciones contemporáneas de la metrópoli -la concentración y la densidad- pero como camino más adecuado para la restauración, en un plano superior, de las formas comunitarias que ella ha dislocado. De hecho, la tira de viviendas flotando sobre sus columnas en una cultivada extensión verde no es simplemente el resultado de una combinación de motivos higiénicos (contra el hacinamiento de la ciudad especulativa) y técnicos (la utilización industrial de los nuevos materiales, el hormigón armado, el acero y el vidrio) para responder con racionalidad y eficiencia a las nuevas demandas masivas de habitación; es la búsqueda de recuperación de la doble armonía perdida en la metrópoli moderna, hacia adentro en la comunidad (y por eso cada unidad se piensa como un nuevo «falansterio» con servicios comunes para las necesidades sociales y culturales de la vecindad) y hacia afuera en la naturaleza. Y si pudiera ser criticable la poca atención que en el proyecto de estas viviendas se le prestaba a las condiciones de vida efectivas de los grupos a los que estaban dirigidas, debe comprenderse que esta arquitectura buscaba modificar los hábitos y las relaciones con la ciudad de toda la población, no sólo de sus segmentos más necesitados: en verdad, esa necesidad era pensada como virtud, ya que en la vivienda social se esperaba que germinara una transformación vanguardista del conjunto de la vida metropolitana. Para la arquitectura modernista, todos los habitantes metropolitanos, migrantes o no -y no hay que olvidarse de que, como señaló Raymond Williams (1997), la respuesta cultural de la vanguardia a la metrópoli también puede explicarse en el origen «aldeano» de buena parte de los artistas que reaccionaban con fascinación y extrañamiento ante la gran ciudad-, son seres alienados que podrán reencontrarse en las nuevas comunidades que los grandes conjuntos habitacionales les ofrecen.

Pero esta noción modernista-voluntarista de comunidad debió enfrentar una alternativa que se iba a traducir, en los años cincuenta, en una política panamericanista de vivienda social bien diferente: la política de apoyo económico y técnico a la autoconstrucción, confirmatoria «de las tradiciones y costumbres de la vida local», como sostenía en 1953 una comisión ad hoc de la Unión Panamericana (1954: 16). El modelo de la construcción con «esfuerzo propio y ayuda mutua» partía de un diagnóstico económico -es imposible resolver el impresionante déficit de vivienda con los escasos recursos de los estados de la región (un promedio del $80 \%$ de la población urbana latinoamericana vivía en condiciones inaceptables de precariedad habitacional, según ese informe)pero lo combinaba con una visión ideológicocultural dominante en las instituciones panamericanas que traducían, así, el consenso técnico norteamericano, tanto sobre el problema de la vivienda en sí -el ideal anglosajón de suburbanización residencial como alternativa a la concentración metropolitana-, como respecto de la población carenciada de los países subdesarrollados -a la que los hábitos del trabajo colectivo servirían como refuerzo de los lazos comunitarios debilitados por el asistencialismo 
estatal y la desmoralización provocada por las condiciones miserables de su vida en la ciudad.

La experiencia que servía de modelo para el desarrollo de esta posición era la que se venía llevando adelante en Puerto Rico donde, por su estatuto colonial, los técnicos norteamericanos pudieron realizar sin obstáculos un experimento radical de reorganización territorial, desarrollo agrícola e industrial, programas de vivienda y modernización de las infraestructuras sanitarias, escolares, viales y turísticas, de notables efectos en la redistribución social, en un todo de acuerdo con esa combinación de tecnocracia y reformismo populista que supuso el clima ideológico del New Deal. Así, la isla se convirtió en un campo de práctica avanzada de la planificación norteamericana (allí se concibió el comprehensive planning, dominante en las siguientes décadas) $y$, al mismo tiempo, en un «microcosmos» ideal de acuerdo a la expresión de Harvey Perloff (1950: 24)- para experimentar con «los problemas y aspiraciones [...] de las regiones superpobladas y subdesarrolladas». ${ }^{33}$ El proceso había comenzado en 1941 con la gobernación de Rexford Tugwell quien había sido subsecretario de Agricultura de Roosevelt y jefe de la Resettlement Administration, la agencia federal encargada de afrontar la escasez de alojamientos urbanos y rurales durante la crisis- y continuó luego de 1946 con las gobernaciones del Partido Popular Democrático de Muñoz Marín y la Bootstrap Operation. ${ }^{34}$

En la cuestión de la vivienda, el «modelo portorriqueño» se resumía en una novedosa política de rehabilitación de arrabales -a través del Programa de Tierras y Servicios Públicosmediante la cual el gobierno saneaba las tierras e instalaba los servicios y las familias se construían las viviendas de acuerdo a planos-tipo muy sencillos, con posibilidad de crecimiento futuro; un sistema que daba resultados mucho más rápidos y menos conflictivos que las políticas de erradicación y reemplazo por grandes conjuntos habitacionales. Estas fueron las bases que tomó la Unión Panamericana, que había organizado en 1949 su Sección de Vivienda y Planificación para canalizar los fondos otorgados por el «Punto IV»-uno de los puntos programáticos del discurso de asunción del presidente Truman en ese mismo año, que instauró como política de estado la asistencia técnica a los países subdesarrollados. Francis Violich, un planificador californiano que en la Unión Panamericana estaba comenzando una larga carrera de especialización en la región, había confeccionado el proyecto de la Sección Vivienda a partir de una estadía de estudio en Caracas, de la que extrajo un análisis muy crítico de la «vía latinoamericana» para la vivienda social: Ios grandes conjuntos habitacionales de iniciativa pública eran inadecuados, insuficientes y nunca llegaban a la población realmente necesitada, lo que terminaba resultando funcional al crecimiento descontrolado de los barrios de invasión. ${ }^{35} \mathrm{La}$ dirección de la Sección quedó a cargo de Anatole Solow, quien impulsó la creación, en 1951, del Centro Interamericano de Vivienda (CINVA) en Bogotá, cumpliendo uno de los principales postulados del Congreso Panamericano de Vivienda Popular que se había celebrado en Buenos Aires en 1939, donde funcionarios y expertos de toda la región habían señalado la necesidad de un centro de formación técnica y experimentación (Solow y Masis, 1950). Y el CINVA funcionó como una caja de resonancia de la planificación portorriqueña, llegando a ser en las siguientes décadas un núcleo de adiestramiento masivo para la puesta en práctica de los programas de asistencia técnica en proyectos de vivienda económica por ayuda mutua con financiamiento norteamericano, y de difusión de la manualística correspondiente (Rivera Páez, 2002).

Hacia 1959, cuando se realiza la conferencia de Santiago de Chile, es posible reconocer una distribución geográfica bastante nítida de ambos modelos en el mapa latinoamericano, con dominio de la política de grandes conjuntos habitacionales en México y Sudamérica y de la política de la ayuda mutua en Colombia y los países centroamericanos - donde el CINVA y, más en general, las instituciones panamericanas tenían una presencia muy activa-, aunque esto deba ser matizado por el hecho de que todos los países que tenían en marcha acuerdos de asistencia técnica con los Estados Unidos implementaban en proporciones variadas programas de micro-emprendimientos de vivienda urbana y rural (Chile, Perú y Brasil, claramente), así como los países que seguían la «vía panamericana» no dejaron por eso de realizar unidades de habitación paradigmáticamente modernistas (como muestran las contrataciones de José Luis Sert, uno de los principales «vanguardistas-expertos», para la realización de urbanizaciones en Bogotá y Puerto Rico, entre muchos ejemplos) (ver Liernur, 2004). Pero las relaciones entre ambas «vías», latinoamericana y panamericana, más allá del pragmatismo de los gobiernos cuando hay programas de asistencia técnica y, especialmente, financiera en juego, eran a la vez tensas e intrincadas. Porque si las instituciones panamericanas y el intento de Estados Unidos de convertir la experiencia portorriqueña en un modelo para todo el continente generaban enormes resistencias en los equipos técnicos y políticos locales, ${ }^{36}$ al mismo tiempo, sus propuestas de ayuda mutua y autoconstrucción asistida sintonizaban con las posiciones más radicalmente comunitaristas y más próximas a la militancia social en las propias poblaciones, como muestran las iniciativas mencionadas de urbanización de las favelas, llevadas adelante por sectores de la Iglesia. 
7. Puede parecer paradójico, por cierto, en relación con las imágenes establecidas de las relaciones entre los países latinoamericanos y los Estados Unidos en el período, lo que surge de esta somera revisión de las políticas de vivienda: las instituciones oficiales y los funcionarios de los países latinoamericanos parecen poco remisos a aceptar la «ingerencia» norteamericana, mientras que las agrupaciones de base parecen confluir de hecho con ella. Y en el reverso de esta paradoja, lo que la historia de la planificación nos muestra es algo no siempre fácil de advertir en las historias de las ciencias sociales: el reformismo populista y basista (también, desde ya, pleno de paternalismo y «salvacionismo liberal», por usar los términos de Miceli, 1990: 28), muchas veces con visos de radicalismo, que los técnicos norteamericanos dedicados a la cooperación con América Latina transportaron directamente de la experiencia del New Deal, que parece haber migrado en bloque al sur ante las poco propicias condiciones que Norteamérica le ofrecía al progresismo en los años cincuenta.

Ahora bien, de la heterogénea confluencia de intereses en el terreno de la «participación popular», donde lo más unificador parece ser el rechazo a las imágenes monumentalista del estado y universalista de la sociedad que los conjuntos habitacionales portaban, en los años sesenta va a ir emergiendo una posición más drástica, que va a ver en la autoconstrucción popular y la consolidación de sus núcleos de residencia una verdadera alternativa a los dilemas de la modernidad urbana latinoamericana ( $y$, más en general, «tercermundista»). Así como el paradigma modernista significaba la disolución de todo resabio de aldea tradicional en la ciudad, para reorganizar el conjunto metropolitano como una articulación novedosa de comunidades funcionales abstractas, y el paradigma comunitarista suponía la radicación consolidada de «la aldea» y su integración a la ciudad como parte con iguales derechos, así las nuevas posiciones van a ir más allá, proponiendo a «la aldea» como célula regeneradora de los males de la sociedad moderna, retomando casi literalmente la función moralizadora que le atribuía Robert Park.

El campo de la arquitectura estaba bien abonado para que esa respuesta germinara, atravesado por la oleada de rebelión de posguerra contra la burocratización y mercantilización del funcionalismo de las vanguardias modernistas en el nuevo mundo construido por la expansión capitalista. Una reacción en muchos sentidos «antropológica» contra el mundo moderno, que podía manifestarse en la reivindicación romántica de la arquitectura vernácula -como la que llevaban adelante Bernard Rudofsky con su célebre muestra "Arquitectura sin arquitectos», o Aldo Van Eyck con su serie de publicaciones sobre la construcción popular en el Sahara-, o en las nuevas aproximaciones a los problemas metropolitanos que buscaban mostrarle a los planificadores las «dimensiones ocultas»-por utilizar la fórmula con que Edward Hall titulaba sus estudios de antropología espacial- de la vida urbana como experiencia simbólica y cultural. ${ }^{37}$

Por supuesto, este debate también incidió en la arquitectura de los grandes conjuntos habitacionales, a través de investigaciones tipológicas que en los años sesenta intentaron incorporar elementos de la cultura del habitar de los sectores populares a los que teóricamente se dirigían (patios, terrazas, variedad volumétrica). Pero su expresión más sintomática en lo que hace a la vivienda social en América Latina -como parte de un problema común a todo el mundo subdesarrollado- se encuentra en las experiencias de autoconstrucción, tal cual fueron elaboradas por el arquitecto inglés John Turner durante varias estadías en Lima.

Turner había llegado a Perú en 1957 invitado por Eduardo Neira, a quien había conocido en una reunión del Congreso Internacional de Arquitectos Modernos (CIAM) en Venecia en 1950 y con el que luego estableció relaciones más firmes durante los estudios de posgrado que realizó en Liverpool. ${ }^{38}$ Según el relato de Turner, cuando Neira lo convocó a integrarse a la Oficina de Asistencia Técnica a las Urbanizaciones Populares que había creado en 1955 en Arequipa, le dio como única bibliografía los manuales portorriqueños de autoconstrucción comunitaria por esfuerzo propio, que se convirtieron en su primer contacto con el tema y en su exclusiva guía cuando tuvieron que enfrentar las consecuencias del terremoto de 1958, que dejó sin vivienda a prácticamente el 50\% de la población arequipeña (Chávez, 2000). A partir de entonces, Turner se convirtió en una especie de etnógrafo de la construcción popular, en trabajos de campo en las barriadas limeñas realizados en diálogo con el antropólogo norteamericano William Mangin, y en un propagandista internacional de la alternativa participativa para la vivienda social. ${ }^{39}$

El razonamiento partía de bases estrictamente pragmáticas y utilitarias, en el sentido de que desencializaba la vivienda de los pobres mostrando que se trataba para ellos de un arma de supervivencia, y su hábitat, de un medio de vida eficiente en la economía urbana, más que de un problema cultural. Pero rápidamente se pasaba a una idealización de la vida en las barriadas (que tenían «un nivel más elevado que numerosos distritos de Lima que se habían desarrollado legalmente») y, especialmente, de sus habitantes, que eran mucho más libres que los pobres de la sociedades ricas. ${ }^{40} \mathrm{Y}$ si parecía evidente que tenían objetivos conformistas, de acomodación instrumental a la sociedad establecida, al mismo tiempo, como afirmaba Mangin en 1963, la 
imposibilidad de que en el Perú se produjesen los cambios acelerados que se necesitaban para satisfacer esas ambiciones reformistas de progreso social, los llevarían a la frustración, convirtiéndolos en actores objetivos del cambio: «Es posible que cuando los niños [los hijos de la primera generación de ocupantes ilegales] comprendan este hecho, hagan realidad la actual profecía paranoica de muchos peruanos de clase media y alta que consideran a la población de las barriadas como rebelde y revolucionaria» (Mangin, 1969: 21).

Durante los años sesenta y los primeros setenta no quedaba margen de duda acerca de que se había tratado de una profecía autocumplida, y estas posiciones a favor de la vivienda social participativa formaron claramente parte del amplio lote de perspectivas de izquierda, al compás de una fortísima oleada de movilizaciones populares urbanas que instaló a «los aldeanos», por primera vez, en un lugar destacadísimo de la escena política de la ciudad. Gobiernos de muy diferente signo tuvieron que aceptar la realidad y el derecho de las invasiones y establecer políticas para su consolidación, y el pensamiento social se lanzó a diversas operaciones teóricas para incorporar estas «luchas por el consumo» en un lugar destacado de la agenda de investigación (buena parte del debate sobre la «urbanización dependiente» y las «teorías de la marginalidad» se explica en la fuerza con que habían irrumpido los «nuevos sujetos sociales» definiendo una supuesta vía latinoamericana a la revolución).

Pero en los años ochenta y noventa -luego del franco retroceso de aquel protagonismo político, uno de los blancos predilectos de los golpes dictatoriales y los procesos autoritarios en los años setenta en la región- aquellas posiciones pudieron ser reinterpretadas tanto en clave neoliberal como neopopulista. De lo primero da un ejemplo inmejorable el economista peruano Hernando de Soto (1986), que en El otro sendero también presentó «el problema» como «la solución», pero para mostrar ahora a los pobladores de las barriadas como activos agentes de la iniciativa privada obstaculizados por un estado paternalista e ineficiente, cuyas anteojeras burocráticas y prejuicios asistencialistas condenan todo ese inmenso movimiento económico real a la ilegalidad. ${ }^{41}$ Entonces se hizo más claro el tipo de operación ideológica que auspiciaba la política de autoayuda del Banco Mundial, así como se resignificó el rol de consultores de organismos internacionales de algunas de las figuras revulsivas de las décadas anteriores, y las propias ambigüedades de aquel culturalismo antropológico: por ejemplo, el periodista Álvaro Vargas Llosa (2004) pudo sostener recientemente que Mangin fue «el hombre que se adelantó treinta años» al comprender que en las barriadas «germinaba no una revolución proletaria, sino una economía de mercado».

La clave neopopulista, por su parte, es la que se consuela ante el fracaso de aquellas promesas revolucionarias con la evidencia del fracaso no menos estruendoso de las anteriores ambiciones desarrollistas, celebrando en el protagonismo de los «aldeanos» la inversión más carnavalesca que libertaria consolidada como escenario definitivo de las metrópolis latinoamericanas. Como ha escrito Abelardo Sánchez León (1988: 207) -e insistimos en autores peruanos apenas como evidencia del intensísimo laboratorio que el caso de las barriadas de Lima representó durante todo ese largo ciclo para el pensamiento latinoamericano-, «si hace siglos, durante la colonia, a los indios se les encerraba en zonas bajo cuatro murallas, hoy en día los sectores acomodados se encuentran en ghettos residenciales rodeados por aquellos que consideraban bárbaros y que han llegado al corazón o al hígado de este país...». O podemos acudir a uno de los analistas más lúcidos de la investigación urbana latinoamericana, que la acompañó con erudición e ironía desde sus mismos comienzos en la década de 1950 oponiendo un consecuente populismo culturalista a las ilusiones ilustradas de reformistas y revolucionarios: "Por primera vez desde la conquista europea -escribía Richard Morse en los años ochenta- la ciudad no representa un bastión intruso en el dominio rural ni constituye un centro de control sobre el mismo. La Nación ha invadido la ciudad. El espacio físico y social urbano refleja ahora a la sociedad nacional como un todo» (Morse, 1989: 75-76). ${ }^{42}$

8. El debate entre Redfield y Lewis sobre la adaptación de los «aldeanos» a la ciudad fue la modulación específica de un problema antropológico que, entre los años cuarenta y los setenta, encontraría ecos en los más variados rincones del pensamiento urbano, social y político latinoamericano, saturando sus significaciones. Por eso, por su gran capilaridad, es posible utilizarlo como un papel de tornasol para testear las diferentes reacciones de cada uno de los elementos que entraron en resonancia con él, con la aspiración de que así podrían iluminarse zonas de historicidad algo diversas de las ya transitadas por los enfoques más específicos sobre los debates políticos, sociológicos o urbanos del período.

En ese sentido, intenté mostrar que el arco abierto entre la propuesta analítica de Redfield y el «ajuste» lewisiano puso el horizonte universalista-reformista dentro del cual pudo surgir una reflexión específica sobre la «ciudad latinoamericana», con un matiz atenuado del dualismo tradición/modernidad que mantenía la confianza en el cambio social, aunque sabía que éste ya no recorrería exactamente el itinerario 
trazado por la experiencia de la ciudad europea o norteamericana. En ese primer estadio de la reflexión urbana, contemporáneo de la institucionalización de las ciencias sociales en la región, el auge del pensamiento cepalino y el optimismo desarrollista, ya se había procesado una primera revisión del debate que puso el acento en las críticas a Redfield de un modo en que, con frecuencia, le daba la razón a Lewis, oponiéndolos sin matices. Las críticas a Redfield se centraban en tres aspectos: el esquematismo abstracto de sus tipos polares (la inexistencia de algo empíricamente reconocible como «sociedad folk» o «sociedad urbana»), el pretendido universalismo del continuo que se establecía entre ellos, y, como contracara de esto último, el «etnocentrismo occidental» de la dicotomía, de acuerdo a los términos con que Philip Hauser, apoyándose decididamente en Lewis, denunciaba su inadecuación para las ciudades del mundo en desarrollo (Hauser y Schnorre, 1965). ${ }^{43}$ Francisco Benet (1963-1964) iría más allá, criticando ya no el «etno» sino el «eurocentrismo» en sentido estricto de la noción de «continuo», porque imponía dicotomías importadas de Europa que tampoco podían reconocerse en los Estados Unidos, donde nunca habría existido una cultura rural. ${ }^{44}$

Pero aunque los teóricos latinoamericanos conocían bien esas críticas y en buena medida las compartían (y el nombre de Hauser entre los que las esgrimen desde temprano es la mejor demostración), la idea de «continuo» seguía dominando como la base desde la cual se organizaba el conjunto de la problemática, el poderoso instrumento para pensar la integración de los «aldeanos» a un proceso de cambio social que imaginaban trastornando desde las ciudades las desiguales estructuras tradicionales de los países latinoamericanos. El propio esfuerzo de comprensión del carácter de las «aldeas» que surgían en las ciudades les mostraba que el mero avance económico y el desarrollo industrial no iban a producir por sí solos esa integración: la necesidad de encontrar nuevas categorías para la «ciudad latinoamericana» es una demostración del desfasaje productivo que se abre hacia finales de los años cincuenta entre los modelos de referencia y la reflexión local. En la ambigüedad de ese desfasaje irresuelto, entre la necesidad universalista y la evidencia empírica de la reforma, se despliega a mi juicio el momento más original de la reflexión urbana latinoamericana.

A partir de entonces, a lo largo de la década de 1960 se podría señalar el surgimiento de otros dos estadios de reflexión sobre el problema que cierran, a su modo, aquel horizonte. Uno, en vinculación con las posiciones radicalizadas sobre el tema de la vivienda popular, que podríamos llamar monismo radical, ya que puso el foco en la necesidad de eliminar todo resabio de «marginalidad» que pudiera desprenderse de aquel dualismo anterior, como manifestación extrema de la voluntad de normalizar y legitimar un equipamiento intelectual específico para pensar el fenómeno de la «ciudad latinoamericana». Estas investigaciones surgieron de un poderoso impulso de identificación política y cultural con «los aldeanos», insistiendo en la esencial homogeneidad de los procesos de urbanización en los sectores de mayor pobreza, más allá de la especificidad de su hábitat en la ciudad o de su origen dentro o fuera de ella. Es decir, la idea de «continuo» quedaba directamente anulada por la necesidad de reivindicar el carácter plenamente urbano de la experiencia de la vida en los barrios populares, contra las anteriores descripciones que veían en ellos una «intrusión rural». El matrimonio de antropólogos norteamericanos Anthony y Elizabeth Leeds realizó estudios sobre las favelas en Río muy característicos de este estadio: en contacto directo con las investigaciones de Turner y Mangin, con quienes colaboraron en varias oportunidades en el intento de trazar hipótesis comparativas, los Leeds buscaron desmitificar el carácter «aldeano» de la favela para mostrar que participaba con altas dosis de creatividad de las actitudes y valores de la ciudad moderna, como parte inescindible de ella (Leeds y Leeds, 1972). ${ }^{45}$

En la línea de las críticas que ya habían señalado el etnocentrismo implícito en la equivalencia de «integración» y «occidentalización», los Leeds propusieron entender los términos propios en que la favela se integraba en un sistema urbano mayor, junto a una gama completa de ambientes socioresidenciales de la pobreza que organizaba un conjunto mucho más matizado y plural que el que surgía de la reducción dualista del esquema favela-tradición / ciudad-modernidad. Y así como mostraban la plena integración en términos económicos, sociales y políticos de la favela con el mundo urbano y sus valores -dando una pintura del favelado que lo mostraba como un ingenioso oportunista a la pesca de las inmensas oportunidades que la ciudad y sus mercados formales e informales ofrecían para la movilidad social-, por otra parte, a través de un estilo de investigación participante que supuso una inmersión total en la vida de la favela, mostraron que ésta tenía una estratificación social interna sumamente compleja -tanto como la de la misma ciudad-, compuesta de niveles de status, grupos y redes que eliminaba cualquier simplificación comunitarista centrada en la familia y los lazos primarios.

Por eso rechazaron el procedimiento metodológico de Lewis, porque el foco analítico en la interioridad de la familia creaba la ilusión de un funcionamiento tradicional que impedía siquiera atisbar la novedad de las redes en que sus miembros estaban inmersos. Más en general, 
estas posiciones discutieron fuertemente con la noción de «cultura de la pobreza» como responsable central en la reproducción académica y política de los prejuicios sobre los pobres urbanos. Pero es importante aclarar que ya no se trataba de una polémica con aquel Lewis que indagaba en los recursos con que los migrantes se «ajustaban» a través de su propia cultura a la de la ciudad -como había hecho en «Urbanization without Breakdown» y hasta «La cultura de la vecindad» de comienzos de los sesenta, textos que siguieron utilizándose positivamente en los debates sobre las migraciones urbanas-, sino con un Lewis que, a partir de la estabilización de la «cultura de la pobreza» como categoría también universalista (a través de trabajos que desarrolló en la India, en Puerto Rico, en los Estados Unidos, continuando el estilo de reportaje colectivo de Five families), fue desarrollando una visión miserabilista de los pobres urbanos que los situaba exclusivamente en la carencia y la marginalidad, como seres indefensos y frustrados, condenados a reproducir de modo incesante las mismas condiciones culturales que habían originado su estado de pobreza. ${ }^{46}$

Y si esta visión tardía de Lewis restringía la acción del estudioso a la denuncia o el asistencialismo, la visión más comprometida del monismo radical, al mismo tiempo, le planteaba serias dificultades conceptuales a la perspectiva de izquierda de la que se sentía partícipe. Así se le señalaba, por ejemplo, que la idea de que la favela no es el problema, sino la solución, que los Leeds compartían con Mangin, le quitaba toda dramaticidad a las condiciones de vida reales de los favelados, «normalizando» su situación de indigencia; o también, desde análisis marxistas, que la propuesta de autoconstrucción y autourbanización significaba enmascarar con un participacionismo progresista la sobreexplotación de los favelados, que se veían obligados a producir también por su cuenta los medios de vida necesarios para garantizar su reproducción como fuerza de trabajo; o que el énfasis en la idea de integración mostraba que los favelados eran «grupos adaptativos y no revolucionarios» (Funes, 1972: 167), empeñados en un ascenso social que los distraía de cualquier tipo de esfuerzo organizativo transformador. ${ }^{47}$

Finalmente, el otro estadio de la reflexión que me interesa destacar, producto en parte de la necesidad de salir de las encrucijadas que le planteaba al pensamiento de izquierda el monismo radical, fue un regreso a la idea de marginalidad, pero positivizada: un dualismo exasperado. Aquí hará su otro camino la noción de «cultura de la pobreza», ya completamente independizada de Lewis, convirtiéndola en cultura radicalmente otra, portadora de valores autónomos capaces de ofrecer una alternativa global a los valores burgueses de la civilización urbana occidental. Es el enfoque polarizado, característico de las teorías de la «urbanización dependiente», que buscó probar que los sectores «marginales» eran una expresión ineliminable de las condiciones de dependencia en que se desarrolla el capitalismo en nuestros países, encarnando su propia contradicción interna, de la que podría llegar a salir, por lo tanto, su superación. ${ }^{48}$ Para Aníbal Quijano, por ejemplo, que desarrolló en la CEPAL una de las visiones más elaboradas de la teoría de la «urbanización dependiente», la «presencia de elementos culturales de procedencia rural» en las ciudades latinoamericanas estaba levantando «una alternativa cultural» frente a la mas extendida «cultura urbana dependiente» formada «con modelos y elementos procedentes de las metrópolis externas dominantes» (Quijano, 1968: 7). ${ }^{49}$ La barriada se convertía, así, en la incrustación subversiva de una alternativa político-cultural al orden dominante en su mismo seno, la ciudad -es decir que por una vía curiosa encontramos la clásica ambigüedad frente a la ciudad de las posiciones de Chicago, transfigurada en franca antipatía.

$Y$ aunque tenían posiciones en muchos órdenes diversas, tales conclusiones no eran demasiado disímiles de las que obtenía Manuel Castells, que elaboró buena parte de sus hipótesis sobre la «cuestión urbana» en el Santiago de Chile de comienzos de los años setenta, con el fondo de uno de los episodios más intensos de protagonismo político del reclamo habitacional. ${ }^{50}$ Castells discutía la noción de «marginalidad», explicando que los sectores a los que se encuadraba dentro de ella por razones combinadas del mercado laboral y el mercado habitacional capitalistas, tenían sin embargo una altísima organización social (mucho mayor que el resto de los sectores urbanos), ofreciendo un modelo alternativo antagónico a la cultura urbana sin más. Y es importante recordar aquí que, en el libro que lo hizo famoso -y marcó a fuego el pensamiento urbano durante más de una década-, Castells dedicó una parte importante de su esfuerzo teórico a desmontar las hipótesis chicaguianas del urbanismo «como forma de vida»y «la interpretación evolucionista de la historia humana implícita en el continuo folk-urbano» (Castells, 1974b: 99). Desde el estructuralismo althuseriano Castells discutía la ideología implícita en la noción de «cultura urbana», proponiéndola como un mito tranquilizador para enmascarar los conflictos estructurales que atraviesan la sociedad de clases; y desde la teoría de la dependencia, señalaba que el principal de esos conflictos en las ciudades latinoamericanas lo proporcionaba la irreductibilidad de aquel mundo «marginal» opuesto al «sector moderno integrado bajo el control de los monopolios» y alentado por el canto de sirenas de la modernización y el progresismo 
urbano que proponía el Estado con sus reformas urbanas. Si la ciudad latinoamericana era un eslabón principal del sistema de dependencia, expandiendo por toda la nación desde su lugar de primacía las redes del «colonialismo interno», la importación de ese conflicto en el seno del mundo urbano era completamente decisiva para producir alineamientos de clase disruptivos del orden social imperante (Castells, 1973: 89).

Por supuesto que ahora Chile se leía en línea con Cuba, donde las políticas urbanas de la Revolución, especialmente la radical descentralización de La Habana -que como medida técnica formaba parte del repertorio más convencional de la planificación desarrollista, pero en Cuba le adicionaba un plus político «antiurbano» por la visión de la capital como síntesis ideológica del régimen depuesto y último bastión social a conquistar por una revolución que había venido del campo-, alimentaban la desconfianza en los efectos conformistas de la ciudad. Como había escrito ya Horowitz en 1966, por el carácter específico que la «dicotomía urbana-rural» asumía en las condiciones de dependencia de América Latina, «la ciudad se convierte en el área reformadora»-»representación de las necesidades y ambiciones de la clase media»y el campo "se vuelve la zona revolucionaria» -en verdad, la «expresión polarizada de la reacción y la revolución: de las soluciones totales para los problemas totales» (Horowitz, 1966: 90). Este parecía ser, en definitiva, el rol de los «aldeanos» en la ciudad: introducir su presencia desestabilizadora ante la inviabilidad de una cooptación reformista como la que habían sufrido los sectores obreros tradicionales. Y así, luego de tres décadas en que la «explosión urbana» había relativizado la centralidad de la cuestión rural en la cultura latinoamericana, se asistía a una nueva inversión, que resituaba por completo la oposición campo/ciudad.

Es posible encontrar este tono antiurbano bastante generalizado a finales de la década de 1960, como expresión de la crisis de confianza en la propia modernización; pero debe destacarse que no fue poco discutido dentro del pensamiento urbano de izquierda, como muestra la obra de Paul Singer, seguramente uno de los polemistas más lúcidos entre los que enfrentó las hipótesis de la teoría de la dependencia con instrumentos de la economía urbana marxista. ${ }^{51}$ Ya Francisco Sabatini (1977: 62) ha destacado el modo en que Singer relativizó la discusión sobre si los migrantes formaban o no comunidades cerradas a la sociedad urbana, explicando que eso no estaba en relación con algún carácter esencial de la cultura «aldeana» en la ciudad, sino con los ciclos de la economía urbana, que cuando está en expansión ofrece empleo e integración, y cuando está en recesión obliga a los grupos expulsados del mercado de trabajo a organizarse para la subsistencia en forma «comunitaria» y autosuficiente. Es decir, el monismo o el marginalismo podrían ser no sólo el resultado de los marcos teórico-ideológicos de comprensión con que los estudiosos encaraban el problema, sino de momentos en los ciclos económicos de las ciudades que les mostraban caras aparentemente contradictorias del mismo fenómeno. ${ }^{52}$

Y siguiendo un razonamiento análogo, que se apoyaba en un exhaustivo estado de la cuestión sobre el tema a finales de la década de 1960, Morse detectaba un "dilema abrumador» para el pensamiento urbano: «Expresado en los términos más crudos, diremos que la cohesión social de los grupos urbanos 'marginales' reúne fuerzas bajo la adversidad y la hostilidad, y retrocede ante la tolerancia y la benevolencia». Y resulta especialmente significativo para nuestro enfoque que, en una nota al pie de esa misma frase, con su habitual modo contrariar los consensos establecidos, Morse ironice sobre el revisionismo sociológico que dominaba entre sus contemporáneos y proponga un retorno a Chicago y a las teorías generales del cambio social: «Las investigaciones realizadas en los tugurios y barriadas latinoamericanas están saturadas con un canto de guerra en contra de los venerados modelos teóricos de la sociedad urbana. Lo que prueban las nuevas interpretaciones no es tanto el etnocentrismo de Maine, Durkheim o Wirth como la ingenuidad de la ciencia social norteamericana contemporánea y su incapacidad para tratar simultáneamente con modelos generalizados y sistemas culturales. La 'cultura de la pobreza' invita a la misma inversión malévola que practicó Marx con la 'filosofía de la miseria' de Proudhon» (Morse, 1971: 43).

Por fin, quizás esta sensación de fin de un ciclo en el pensamiento social, expresada irónicamente por Morse, pueda explicar que en una fecha tan tardía como 1974, cuando ya Redfield había sido negado una y mil veces, Gino Germani haya preparado para una editorial italiana una antología de textos sobre el tema, Urbanizzazione e modernizzazione, dándole un lugar de preeminencia al artículo que Redfield escribió con Milton Singer, «El papel cultural de las ciudades» y, más aún, haya intentado, en su introducción al volumen, un esfuerzo extraordinario de compatibilización de las teorías clásicas con buena parte de las nuevas aproximaciones, todavía a la búsqueda de una teoría general de la modernización que fuera capaz de incorporar, sin distorsionarla, la experiencia de la urbanización latinoamericana. ${ }^{53}$ Aunque también podríamos preguntarnos -con un ánimo relativista análogo al de Paul Singer- si la búsqueda de universales de Germani y su reformismo empedernido no podrían ser entendidos como impuestos por la peculiar ciudad desde la que se interrogaba sobre la urbanización latinoamericana, Buenos Aires, uno de los casos de mayor modernidad e integración del continente (lo que no implica que Germani fuese optimista respecto del tipo de 
sociedad que esa modernidad e integración habían generado, en absoluto). En todo caso $-y$ este parece un razonable modo de terminar este recorrido ya demasiado prolongado-, el retorno en 1974 a esas viejas preguntas de matriz antropológica sobre la adaptación/aculturación en una sociedad en transición, realizado por una de las figuras más atentas a las derivas del pensamiento social de su tiempo, más que como un simple anacronismo, quizás deba ser tomado como indicio de que nos encontramos frente a un universo de cuestiones y posiciones teóricas que seguían -y siguen- abiertas, porque no son de aquellas que pueden ser «superadas» por el avance del conocimiento. Las «aldeas» en la ciudad latinoamericana han pasado de ser «problemas» a «soluciones», de «estigmas» a «alternativas» y viceversa, pero su presencia cada vez más característica y sus déficits, siempre tan agudos aunque cada vez más masivos, nos siguen enfrentando a desafíos principales del pensamiento tanto como de la política urbana, sobre los que aquel debate antropológico quizás tenga, todavía, algo que decir.

\section{Bibliografía}

Alteridades. 1994. Revista Alteridades, año 4, nº 7, México, Universidad Autónoma Metropolitana Iztapalapa. Número especial dedicado a Oscar Lewis, con artículos de E. Nivón y A. R. Mantecón, M. Guttman, J. A. Lozano y otros.

Ballent, A. 2004. Learning from Lima. PREVI, Perú: habitar popular, vivienda masiva y debate arquitectónico, Block $\mathrm{N}^{\circ} 6$, Buenos Aires, Universidad Torcuato Di Tella.

Ballent, A. 2006. Las huellas de la política, Buenos Aires, Editorial de la Universidad Nacional de Quilmes.

Benet, F. 1963-1964. Sociology Uncertain: the Ideology of the Rural-Urban Continuum, en Comparative Studies in Society and History, vol. VI.

Blanco, A. 2003. Política, modernización y desarrollo: una revisión de la recepción de Talcott Parsons en la obra de Gino Germani, Estudios sociológicos, vol. $21, \mathrm{~N}^{\circ} 63$.

Blanco, A. 2006. Razón y modernidad. Gino Germani y la sociología en la Argentina, Buenos Aires, Siglo XXI Editores,

Bonduki, A. 1999. Otra mirada sobre la arquitectura brasileña: la producción de vivienda social (1930-1954), Block. Revista de cultura de la arquitectura, la ciudad y el territorio $\mathrm{N}^{\circ} 4$, Buenos Aires, Universidad Torcuato Di Tella.
Castells, M. 1973. La urbanización dependiente en América Latina, en M. Schteingart (comp.), Urbanización y dependencia en América Latina, Buenos Aires, Ediciones Siap.

Castells, M(comp.). 1974a. Estructura de clases y política urbana en América Latina, Buenos Aires, Ediciones Siap.

Castells, M. 1974b. La cuestión urbana (París, 1972), Madrid, Siglo XXI Editores.

Consejo Interamericano Económico y Social. 1954. El problema de la vivienda de interés social en América Latina, Washington, Unión Panamericana.

Coser, L. 1971. Masters of Sociological Thought, Nueva York, Harcourt Brace Jovanovich.

Costa Pintos, L. 1953. O negro no Rio de Janeiro, São Paulo, Companhia Editora Nacional.

Chávez, R., J. Viloria y M. Zipperer. 2000. Entrevista con John F. C. Turner, Washington, Banco Mundial, uww.worldbank.org/urban/forum2002/docs/turnertkd-spn.pdf.

de Soto, H. 1986. El otro sendero, Lima, Ediciones El Barranco.

Forni, F. 1966. Aspectos sociales de la urbanización, en Jorge E. Hardoy y Carlos Tobar (dirs.), La urbanización en América Latina, Buenos Aires, Editorial del Instituto, 1969.

Friedmann, J. 1968. El futuro de la urbanización en América Latina: algunas observaciones sobre el papel de la periferia, Santiago de Chile, Programa de Asesoría en Desarrollo Urbano y Regional, Fundacion Ford, edición mimeografiada.

Funes, J. C. (ed.). 1972. La ciudad y la región para el desarrollo, Caracas, Comisión de Administración Pública de Venezuela.

Germani, G. (s/f). El proceso de urbanización en la Argentina, folleto $\mathrm{N}^{\circ} 4$, Buenos Aires, Instituto de Sociología de la Universidad de Buenos Aires.

Germani, G. 1967. Investigación sobre los efectos sociales de la urbanización en un área obrera del Gran Buenos Aires, en Hauser, P. et. al., La investigación social en las zonas urbanas (París, 1965), Barcelona, Labor.

Germani, G. 1971. Sociología de la modernización, Buenos Aires, Paidós.

Germani, G. 1972. Migración e integración cultural, en Hauser, P. et. al., La investigación social en las zonas urbanas (París, 1965), Barcelona, Labor. 
Germani, G. (comp.) .1974. Urbanizzazione e modernizzazione, Bologna, II Mulino (publicado en castellano como Urbanización, desarrollo y modernización, Buenos Aires, Paidós, 1976).

González Ortiz, F. y T. Romero Contreras. 1999. Robert Redfield y su influencia en la formación de científicos mexicanos, Ciencia Ergo Sum, vol. 6, ${ }^{\circ}$ 2, Toluca, Universidad Autónoma del Estado de México.

Gorelik, A. 2002. La 'ciudad latinoamericana' como idea, Punto de Vista N ${ }^{\circ} 73$, Buenos Aires.

Gorelik, A. 2004. Miradas sobre Buenos Aires. Historia cultural y crítica urbana, Buenos Aires, Siglo XXI Editores.

Gorelik, A. 2005a. A produção da 'cidade latinoamericana', Tempo Social. Revista de sociología da USP, vol. 17, N 1, São Paulo, Universidade de São Paulo.

Gorelik, A. 2005b. Das vanguardas à Brasília. Cultura urbana e arquitetura na America Latina, Belo Horizonte, Editora UFMG.

Hall, E. 1951. The Silent Language, Nueva York, Knopf.

Hall, E. 1972. La dimensión oculta (Nueva York, 1966), Buenos Aires, Siglo XXI Editores.

Hannerz, U. 1986. Exploración de la ciudad (Nueva York, 1980), México, Fondo de Cultura Económica.

Hauser, P. 1965. Observations on the Urban-Folk and Urban-Rural Dichotomies as Forms of Western Ethnocentrism, en Hauser, P. y L. Schnorre, The Study of Urbanization, Nueva York - Londres - Sidney, John Willey \& Sons.

Hauser, P. (ed.). 1967. La urbanización en América Latina (París, 1962), Buenos Aires, Solar / Hachette.

Hauser, P. y L. Schnorre. 1965. The Study of Urbanization, Nueva York - Londres - Sidney, John Willey \& Sons.

Hirschmann, A. 1973. Desarrollo y América Latina. Obstinación por la esperanza, México, Fondo de Cultura Económica.

Horowitz, I. L. 1966. La política urbana en Latinoamérica, Revista Mexicana de Sociología vol. 28, $\mathrm{N}^{\circ} 1$, Ciudad de México.

Lamparelli, C. 1994. Louis-Joseph Lebret e a pesquisa urbano-regional no Brasil - Crônicas tardias ou história prematura, Revista Espaço e Debates N 37, São Paulo.
Leeds, A. y E. Leeds. 1972. El mito de la ruralidad urbana: experiencia urbana, trabajo y valores de los 'ranchos' de Río de Janeiro y Lima, en Funes, J. C. (ed.) (1972).

Lewis, O. 1944. Social and economic changes for a Mexican Village: Tepoztlán, 1926-1944, América Indígena, $\mathrm{N}^{\circ} 4$, México.

Lewis, O. 195. Life in American Village: Tepoztlan Reestudied, Urbana, University of Illinois Press (traducción en español: Tepoztlán, un pueblo de México, México, J. Moritz, 1960).

Lewis, O. 1952. Urbanization without Breakdown: a Case Study, The Scientific Monthly, vol. 75, N ${ }^{\circ} 1$.

Lewis, O. 1959a. Five Families (Mexican Case Study in the Culture of Poverty, Nueva York, Basic Books (trad. en español: Antropología de la pobreza. Cinco familias, México, Fondo de Cultura Económica, 1961).

Lewis, O. 1959b. La cultura de la vecindad en la ciudad de México, ponencia presentada en el Seminario sobre problemas de la urbanización en América Latina, Santiago de Chile, CEPAL, versión mimeografiada.

Lewis, O. 1964. Los hijos de Sánchez (Nueva York, 1961), México, Fondo de Cultura Económica.

Lewis, O. 1965. Further observations on the folkurban continuum and urbanization with special reference to Mexico City, en Hauser, P. y . Schnorre (1965) The Study of Urbanization, Nueva York Londres - Sidney, John Willey \& Sons.

Lewis, O, K. S. Karol y Carlos Fuentes. 1967. Diálogo sobre la cultura de la pobreza, Cuadernos de la Sociedad Venezolana de Planificación $\mathrm{N}^{\circ} 44$, Caracas (reproducido en Oscar Lewis, La cultura de la pobreza, Barcelona, Anagrama, 1972).

Liernur, J. F. 2004. Vanguardistas versus expertos. Reconstrucción europea, expansión norteamericana y emergencia del 'Tercer Mundo': para una relectura del debate arquitectónico en la segunda posguerra (una mirada desde América Latina), Block $\mathrm{N}^{\circ} 6$, Buenos Aires, Universidad Torcuato Di Tella.

Lynch, K. 1984. La imagen de la ciudad (Cambridge, 1960), Barcelona, Gustavo Gili.

Mangin, W. 1967. Latin American Squatter Settements: a problem and a solution, Latin American Research Review $\mathrm{N}^{\circ} 2$.

Mangin, W. 1969. Historia de un caso de urbanización en el Perú (1963), Cuadernos summa - nueva visión N²29, Buenos Aires. 
Marsal,J. 1967. Cambio social en América Latina. Crítica de algunas interpretaciones dominantes en las ciencias sociales (Princeton, 1965), Buenos Aires, Solar / Hachette.

Martín Frechilla,J.J. 2004. Diálogos reconstruidos para una historia de la Caracas moderna, Caracas, Universidad Central de Venezuela.

Martínez, E. 1999. Introducción, en Park (1999) La ciudad y otros ensayos de ecología urbana, Barcelona, Ediciones del Serba.

Matos Mar, J. 1967. Las barriadas limeñas: un caso de integración a la vida urbana, en Hauser, P. (ed.) (1967).

Matos Mar,J. 1968. Urbanización y barriadas en América del Sur, Lima, Instituto de Estudios Peruanos.

Miceli, S (org.). 1989. História das ciências sociais no Brasil, São Paulo, Vértice.

Miceli, S. 1990. A desilusão americana. Relações acadêmicas entre Brasil e Estados Unidos, São Paulo, Editora Sumaré.

Morse, R. 1971. La investigación urbana latinoamericana: tendencias y planteos, Buenos Aires, Ediciones SIAP.

Morse, R. 1989. Las ciudades como personas, en J. E. Hardoy y R. Morse (comps.), Nuevas perspectivas en los estudios sobre historia urbana latinoamericana, Buenos Aires, Grupo Editor Latinoamericano.

Myers, J. 2002. Un historiador entre dos espejos: El espejo de Próspero veinte años después, Punto de Vista $\mathrm{N}^{\circ} 73$, Buenos Aires.

Nacif Xavier, L. 2000. O Brasil como laboratorio, São Paulo, Bragança Paulista / EDUSF.

Nisbet, R. 1996. La formación del pensamiento sociológico (Nueva York, 1966), Buenos Aires, Amorrortu.

Pantojas-García, E. 1990. Development Strategies as Ideology. Puerto Rico's Export-Led Industrialization Experience, Boulder / Río Piedras, Lynne Rienner Publishers / Editorial de la Universidad de Puerto Rico.

Park, R. 1999. La ciudad y otros ensayos de ecología urbana, Barcelona, Ediciones del Serbal (con selección y estudio introductorio de E. Martínez).

Park, R., E. Burgess y R. McKenzie. 1925. The City, Chicago, University of Chicago Press.

Pearse, A. 1958. Notas sobre a organização social de uma favela de Rio de Janeiro, Educação e Ciencias Sociais, año III, N ${ }^{\circ} 7$, Río de Janeiro.
Pearse, A. 1967. Algunas características de la urbanización en Río de Janeiro, en Hauser, P. (ed.) (1967).

Pearse, A. 1975. The Latin American Peasant, Londres. Routledge.

Perloff, H. S. 1950. Puerto Rico's Economic Future: a Study in Planned Development, Chicago, The University of Chicago Press.

Picó, R. 1962. Puerto Rico: planificación y acción, San Juan, Banco Gubernamental de Fomento para Puerto Rico.

Pizzorno, A. 1967. Introduzione, en R. Park, E. Burgess y R. McKenzie, La città, Turín, Edizioni di Comunitá.

Pradilla, E. 1982. Autoconstrucción, explotación de la fuerza de trabajo y políticas del Estado en América Latina, en E. Pradilla (comp.), Ensayos sobre el problema de la vivienda en América Latina, México, Universidad Autónoma Metropolitana Unidad Xochimilco.

Quijano, A. 1968. Urbanización y tendencias de cambio en la sociedad latinoamericana, documento del Centro de Investigaciones en Desarrollo Urbano y Regional, Santiago de Chile, Pontificia Universidad Católica de Chile.

Rauty, R. 1999. Introduzione, en R. Park, E. Burgess y R. McKenzie, La città, Turín, Edizioni di Comunitá.

Redfield, R. 1930. Tepoztlan, a Mexican Village, Chicago, University of Chicago Press.

Redfield, R. 1941. The Folk Culture of Yucatan, Chicago, The University of Chicago Press.

Redfield, R. 1946. Yucatán: una cultura en transición, México, Fondo de Cultura Económica.

Redfield, R. 1947. The Folk Society, The American Journal of Sociology, vol. 52, $\mathrm{N}^{\circ} 4$, Chicago, The University of Chicago Press.

Redfield, R. 1960. The Little Community (1956), Chicago, The University of Chicago Press.

Rivera Páez, J. A. 2002. El CINVA: un modelo de cooperación técnica, 1951-1972, Tesis de grado, Bogotá, Departamento de Historia, Facultad de Ciencias Humanas, Universidad Nacional de Colombia, mimeo, 2 tomos.

Ruiz Blanco, M. 2003. Vivienda colectiva estatal en Latinoamérica, 1930-1960, Lima, Editorial Hozlo.

Sabatini, F. 1977. La dimensión ambiental de la pobreza urbana en las teorías latinoamericanas de la marginalidad, Eure. Revista Latinoamericana de 
Estudios Urbano Regionales, vol. 8, $\mathrm{N}^{\circ} 23$, Santiago de Chile, CIDU.

Sadler, S. 1998. The Situationist City, Cambridge, The MIT Press.

Sánchez León, A. 1988. Lima y los hijos del desorden, en J. E. Hardoy y R. Morse (comps.), Repensando la ciudad de América Latina, Buenos Aires, Grupo Editor Latinoamericano.

Scott, F. D. 2004. Revisando Arquitectura sin arquitectos, Block $\mathrm{N}^{\circ}$ 6, Buenos Aires, Universidad Torcuato Di Tella.

Segura Escobar, N. y A. Camacho Guizado. 1999. En los cuarenta años de la sociología colombiana, Revista de estudios sociales $\mathrm{N}^{\circ} 4$, Bogotá.

Singer, P. 1975. Economía política de la urbanización, México, Siglo XXI Editores.

Solow, A. y R.Masis. 1959. Cooperación interamericana en el campo de la vivienda y el urbanismo, Nuestra Arquitectura, vol. 21, N 6, Buenos Aires.

Strauven, F. 2004. Aldo Van Eyck. La forma de la relatividad, Block $\mathrm{N}^{\circ} 6$, Buenos Aires, Universidad Torcuato Di Tella.

Turner, J. 1963. Dwelling resources in Latin America, Architectural Design, año XXXIII, N ${ }^{\circ} 8$, Londres.

Turner, J. 1976. Housing by People, Londres, Marion Boyard.

Valladares, L. do P. 1987. Études sur le logement au Brésil, Cahiers du Brésil Contemporain $\mathrm{N}^{\circ} 1$, París, Maison dês Sciences de l'Homme.

Valladares, L. do P. 2005. A invenção da favela. Do mito de origem a favela.com, Río de Janeiro, Editora FGV.

Vargas Llosa, A. 2004. El hombre que se adelantó, columna publicada el 26 de enero de 2004 en Libertad Digital.es, www.libertaddigital.com.

White, M. y L. White. 1967. El intelectual contra la ciudad. De Thomas Jefferson a Frank Lloyd Wright (Cambridge, 1962), Buenos Aires, Ediciones Infinito.

Williams, R. 1997. Las percepciones metropolitanas y la emergencia del Modernismo, en La política del modernismo. Contra los nuevos conformistas (Londres, 1989), Buenos Aires, Manantial (compilación y estudio introductorio: T. Pinkney).
Wirth, L. 1938. Urbanism as a Way of Life, The American Journal of Sociology, vol. 44, $\mathrm{N}^{\circ} 1$, Chicago, The University of Chicago Press.

Zapata, A. 1995. El joven Belaúnde. Historia de la revista El Arquitecto Peruano, Lima, Editorial Minerva.

'Esta situación cambió en las últimas décadas, a partir de la importancia creciente que las nuevas tendencias del "planeamiento estratégico» le han dado a la identidad cultural como reservorio de valores para un exitoso marketing urbano en las condiciones de la globalización, posición con la que, de muy diversas maneras, algunas perspectivas antropológicas de análisis urbano han venido contribuyendo; he desarrollado este aspecto en: "Imaginarios urbanos e imaginación urbana. Para un recorrido por los lugares comunes de los estudios culturales urbanos» (Gorelik, 2004).

2 Para una lectura desde la antropología de la «Escuela de Chicago», ver Hannerz (1986), quien titula uno de los capítulos que dedica al análisis de la «Escuela»: «Etnógrafos de Chicago». Sobre las relaciones entre esa escuela de pensamiento y las teorías de la modernización en América Latina, la referencia clásica es el libro pionero de Juan Marsal (1967), que dedica toda su primera parte a «Los modelos de los científicos sociales norteamericanos», con un capítulo sobre «La antropología y América Latina».

${ }_{3}$ Por supuesto, el interés por la Escuela de Chicago y sus principales figuras siguió vivo en muchos centros intelectuales, no sólo en los Estados Unidos, aunque los principales estudios sobre ella provienen de allí. Ver, por caso, el lugar que dedica a Robert Park el clásico estudio de Lewis Coser (1971), y respecto de traducciones de The City, vale la pena señalar el caso de Italia, donde se realizaron dos ediciones desde los años sesenta, con dos estudios introductorios diferentes que muestran la necesidad de las relecturas: el ya clásico de Alessandro Pizzorno (1967) y el de Raffaele Rauty (1999).

${ }^{4}$ Las comillas de «ciudad latinoamericana» buscan presentarla no como una realidad urbana, que no lo es, sino como la figura del pensamiento social que fue entre los años 1940 y 1970; he desarrollado esta cuestión en Gorelik (2005a).

${ }^{5}$ Sólo como un ejemplo entre muchos, puede citarse a otro scholar norteamericano, el experimentado planificador John Friedmann, que en 1968, cuando ya había suficientes indicios de que ese ciclo desarrollista de la imaginación social estaba agotándose, podía afirmar todavía que «el futuro de América Latina es en cierta medida susceptible de elegirse deliberadamente» (Friedmann, 1968: 37).

${ }^{6}$ Antes de viajar a México, Robert Redfield (18971958) había abandonado su práctica de la abogacía en Chicago; ver: González Ortiz y Romero Contreras (1999).

7 Según Marsal (1967: 67), el libro resultó inaugural de los estudios de comunidad en América Latina.

${ }^{8}$ Sobre el hecho de que Redfield estaba predispuesto a encontrar eso que encontró, ver la respuesta que le dio a Lewis, en un reconocimiento muy original y temprano, como señala Hannerz (1986: 85), de la incidencia de la personalidad del antropólogo en su investigación: ver Redfield (1960:135).

${ }_{9}$ Sobre Oscar Lewis (1914-1970), ver el excelente número que le dedicó la revista Alteridades (1994), con especial énfasis en la importancia de Lewis en la consolidación de la antropología en México. Conviene apuntar que Tepoztlán es hoy conocido,más que como un hito de la antropología, como lugar de peregrinación de la New Age, en un giro muy significativo sobre el rol 
que la combinación de «primitivismo» social y natural pasó a representar en las últimas décadas.

10 La vecindad mexicana es el equivalente del conventillo argentino y el cortiço brasileño.

11 «La vecindad actúa como un amortiguador para los migrantes rurales que llegan a la ciudad, debido a la semejanza entre su cultura y la de las comunidades rurales» (Lewis, 1959b: 19).

12 Como se sabe, las diversas denominaciones indican los modos en que en diferentes países latinoamericanos se nombra un fenómeno que, más allá de lógicas variaciones, puede resumirse del siguiente modo: barrios originados en una invasión ilegal de terrenos vacantes -de propiedad estatal o privada- en las periferias -externas o internas- de la ciudad, sobre los cuales se montan, sin ningún tipo de infraestructura de partida, conjuntos apiñados de viviendas construidas con materiales inicialmente precarios (cartón y chapa) que con el tiempo se van consolidando.

13 Cito de la versión en español del artículo, de acuerdo a la selección que realizó Emilio Martínez (con un muy buen estudio preliminar): Park (1999: 76).

${ }^{14}$ Este artículo también se reproduce en la selección de Emilio Martínez como "La organización de la comunidad y el temperamento romántico» (1925) (Park, 1999: 101-112), pero la expresión citada no corresponde a esa traducción, sino a la del libro de los White (1967: 160).

15 En su capítulo sobre la noción de «comunidad», Nisbet $(1966$, I: 118) ha señalado ese aspecto de la comprensión durkheimiana. Emilio Martínez (1999: 22) argumenta acerca de las diferencias entre el «darwinismo reformista» de Chicago y el «darwinismo social» de Sumner.

${ }^{16}$ Las tres ponencias integran la parte VI. «Migración y urbanización» (Hauser, 1967). Cabe señalar que la ponencia de Oscar Lewis (1959b) no fue reproducida en el libro, pero se la puede ver mencionada en el Anexo III. «Lista de los documentos presentados al Seminario».

17 Matos Mar nació en la región serrana de Ayacucho, muy próxima a Lima, en 1921 y estudió humanidades en la Universidad de San Marcos, Lima, y luego en la École Practique des Hautes Études de la Universidad de París (1953-1954), de donde regresó a Perú para doctorarse en antropología en la Universidad de San Marcos en 1958. A partir de su trabajo sobre las barriadas de Lima comenzó una serie de estudios comparativos en Perú y América del Sur, posiblemente los de mayor exhaustividad de la región para el período: ver Matos Mar (1968). En 1964 creó el Instituto de Estudios Peruanos, que dirigió hasta 1984; entre esa fecha y 1989 fue asesor del gobierno aprista de Alan García, a cuyo término se radicó en México, como miembro del Instituto Panamericano de Historia y Geografía.

${ }^{18}$ Matos Mar integró el grupo «Espacio», la formación arquitectónico-cultural modernizadora liderada por Belaúnde, y fue miembro fundador del partido Acción Popular (entrevista realizada a Matos Mar en ciudad de México, el 27 de septiembre de 2004). Sobre Belaúnde Terry, cfr. Zapata (1995).

19 Sólo para notar la intensidad de la dinámica que intentaba captar Matos Mar, apuntemos que si en 1957 las barriadas representaban el $10 \%$ de la población limeña, muy pocos años después, en 1961, frente a un crecimiento de Lima del $40 \%$, sus barriadas se habían triplicado, llegando a representar, con 480.000 habitantes, casi la tercera parte del total de la población capitalina -datos tomados de un estudio de 1963 del mismo Matos Mar (1968: 165).

20 El CBPE fue creado por Anísio Teixeira, figura central en la reforma educativa brasileña. Luego de su trabajo en Río, Pearse llegaría a tener una dilatada trayectoria en América Latina como experto de Naciones Unidas, algunos de cuyos hitos fueron: la colaboración con el sociólogo colombiano Orlando Fals Borda para la creación del Departamento de Sociología de la
Universidad Nacional de Colombia, donde comenzó un trabajo de investigación participante en áreas rurales, convirtiéndose en una referencia en el tema de la «participación campesina»; la integración del organismo estatal chileno encargado de la reforma agraria durante la presidencia de Frei Montalva; la investigación en Bolivia sobre temas de educación campesina, completando una experiencia sobre la que publicó su principal libro: The Latin American Peasant (Pearse, 1975). Ver: Nacif Xavier (2000) y Segura Escobar y Camacho Guizado (1999).

${ }^{21}$ Ver Valladares (2005: 63-73), que analiza los datos del primer censo oficial específico, el Recenseamento das Favelas do Rio realizado por la Prefectura entre 1947 y 1948, y del primer censo general que abordó las favelas como un sector diferenciado de la ciudad, el Recenseamento Geral de 1950 del Instituto Brasileiro de Geografía e Estatística, para remarcar que en las cifras elevadas había una fuerte mitología. No hemos podido verificar si las cifras que da Pearse, extraídas de un estudio de 1957 del Instituto de Pesquisas e Estudos do Mercado, son confiables y reflejan el crecimiento en los siete años transcurridos (recordemos que, de acuerdo a los estudios de Matos Mar, las barriadas de Lima se triplicaron en apenas cuatro años) o fueron luego desmentidas por un censo posterior.

22 Esto no significa que en las otras ciudades latinoamericanas no hubieran surgido asentamientos ilegales y precarios desde muy temprano, incluso desde la Colonia; ya en tiempos contemporáneos, es habitual que todos los estudios sobre la villa miseria en Buenos Aires, por ejemplo, comiencen remitiendo al «barrio de las latas» que se desarrolló en la Quema de basuras de San Cristóbal Sur desde finales del siglo XIX, o a la «Villa desocupación» que surgió en Retiro con la crisis del año 1930, pero son siempre «antecedentes», que no tuvieron ni continuidad física ni institucional ni social. Por el contrario, la favela (nombre que, como se sabe, remite al «morro de favella» de la batalla de Canudos, utilizado por los veteranos que, de regreso en Río y ante la indiferencia del poder público por su situación de miseria, se instalaron en el morro de Providencia en 1897, rebautizándolo, y que a partir de la década de 1910 comenzó a usarse como un nombre genérico para todas las otras ocupaciones ilegales de morros incluso anteriores) le dio a ese tipo de asentamientos en Río una imagen de estabilidad y continuidad que se impuso en la opinión pública a pesar de su crecimiento cuantitativo y cualitativo a partir de los años 1940, como en el resto de la ciudades latinoamericanas; por eso, uno de los tópicos de los estudios sobre la favela en este período fue demostrar, contra el sentido común, que su población ya no era más la tradicional.

23 Para Valladares (2005: 79), el capítulo de Costa Pinto es «la primera producción sociológica que aborda la favela». Cabe recordar, respecto de la presencia de la UNESCO en todas estas iniciativas, que será también esta institución la que, muy poco tiempo después, le dará a Costa Pintos los recursos para crear en Río de Janeiro el Centro Latino Americano de Pesquisas em Ciências Sociais (CLAPS), primer centro regional de investigaciones sociológicas; ver Miceli (1989).

${ }_{24}$ Sobre el padre Lebret, ver Lamparelli (1994), que muestra que Économie et Humanisme hizo en Brasil la experiencia que le permitió producir una teoría y una práctica para el mundo subdesarrollado. Vale la pena señalar que uno de los miembros de Economie et Humanisme fue el economista espacial François Perroux, que creó la influyente teoría de los «polos de desarrollo». Sobre el estudio de las favelas de SAGMACS, ver Valladares (2005: 86 y ss).

25 Sobre la Cruzada São Sebastião, ver Valladares (2005: 74 y ss.), que se refiere a embates de la derecha como la «Batalla de Río», emprendida en 1948 por el entonces periodista Carlos Lacerda para la erradicación de las favelas. 
${ }^{26}$ Cfr. Valladares (2005), que por esta razón ve en SAGMACS un avance frente a las posiciones «marginalistas», aunque disentimos con ella cuando coloca en esas posiciones al trabajo de Pearse: ver Valladares (1987). En apoyo a nuestra interpretación, sin embargo, cabe destacar que los Leeds, seguramente los principales referentes en la discusión contra el marginalismo, en 1967 encontraban en el trabajo de Pearse una primera refutación de «nociones como 'marginalidad' y aislamiento»; ver Leeds y Leeds (1972: $105)$.

27 La figura de Germani (1911-1979), de indiscutible centralidad en la tradición sociológica argentina, en los últimos años ha sido objeto de atención renovada; destacamos el libro de Blanco (2006), que lo muestra como una figura culturalmente mucho más compleja que la del difusor de la sociología funcionalista en que había quedado estigmatizado. Todavía resta realizar, sin embargo, un análisis del rol de Germani en el desarrollo de los estudios urbanos en la Argentina y, sobre todo, la importancia y los efectos de la aproximación urbana en la propia trayectoria de Germani. Sólo como una breve introducción a la cuestión, vale la pena señalar algunos hitos principales en esa aproximación: a propósito del encargo de UNESCO, Germani realizó, además del primer trabajo de campo en los estudios urbanos, un primer abordaje general sobre el tema, que presenta también en Santiago en 1959 pero no se reproduce en el libro de Hauser (Germani, s/f). En esos años finales de la década de 1950 encaró también el primer estudio sistemático del Gran Buenos Aires, con la colaboración del arquitecto Jorge Goldenberg. Y a través de Hauser y la UNESCO volvió a ser convocado para la redacción del capítulo «Migración e integración cultural» (que en inglés tiene la sugestiva traducción: "Migration and Acculturation») (Germani, 1972), texto que republicó levemente modificado en su Sociología de la modernización (Germani, 1971), donde se integra con otros tres capítulos sobre el tema (más de la mitad del libro). Finalmente, su compilación de 1974, Urbanizzazione e modernizzazione, a la que nos referimos en el final del artículo.

${ }^{28}$ Así lo indica el propio Germani (1967: 233-234). Cabe aclarar, para quienes no conocen Buenos Aires, que la Isla Maciel está en el borde exterior sur de la ciudad de Buenos Aires y que no es propiamente una «isla», ya que el arroyo que antiguamente la separaba de Avellaneda ha sido dragado. Y cabe señalar también, que junto con la encuesta de Germani, el Departamento de Extensión de la UBA llevaba adelante en la Isla Maciel un proyecto experimental de pabellones de vivienda dirigido por el arquitecto Wladimiro Acosta, una de las figuras principales de la renovación arquitectónica desde la década de 1930.

${ }^{29}$ No puedo dejar de anotar, como detalle curioso que marca las transformaciones espectaculares que sufrió la Argentina desde aquellos años, que Germani encuentra que todas las familias de la muestra leen al menos un diario, y que el $50 \%$, repartido por igual en los cinco grupos, leen dos o más, algo seguramente imposible de verificar hoy en sectores de clase media alta.

30 Ver el documento de la Dirección de Asuntos Sociales de las Naciones Unidas, "Algunas consecuencias políticas de la urbanización» (Hauser, 1967: 357).

31 Precisamente así, como estaciones de un continuo rural-urbano, fueron explicadas las presentaciones de 1959 sobre Lima, Río y Buenos Aires por Forni (1969).

32 Nabil Bonduki (1999) ha señalado para el caso del Brasil que la historiografía de la arquitectura ha reparado siempre exclusivamente en los grandes hitos arquitectónicos, descuidando la enorme producción institucional de vivienda social entre las décadas de 1930 y 1950. En nuestro país, el análisis de la producción en vivienda social ha desarrollado una vasta aunque muy desigual bibliografía; sobre los años treinta y cuarenta, ver el excelente libro de Anahi Ballent (2006). Para una visión panorámica de este tema en América Latina, ver Ruiz Blanco (2003)

33 Perloff se fogueó como planificador en una estadía en Puerto Rico en los años cuarenta, luego de lo cual formó parte del equipo con el que Rexford Tugwell -último gobernador colonial de la isla- organizó a su regreso en los Estados Unidos el posgrado en planificación de la Universidad de Chicago, puntal de la renovación de ese campo de estudios en los años cincuenta y sesenta.

${ }^{34}$ Un relato apologético sobre la planificación en Puerto Rico, realizado por uno de sus protagonistas, en Picó (1962); un análisis crítico de la Bootstrap Operation, en Pantojas-García (1990).

35 Francis Violich (1911-2005) fue una figura decisiva en la expansión de la planificación maniera norteamericana por América Latina, tanto por su propia obra como autor y consultor, especialmente en Venezuela, como por la cantidad de planificadores que, a instancias suyas, hicieron los estudios de posgrado en la Universidad de California en Berkeley, el posgrado en planificación que más alumnos latinoamericanos recibió desde comienzos de los años 1950 y hasta mediados de la década de 1960, cuando aparecieron los primeros cursos en instituciones académicas de la región. Ver el interesantísimo reportaje que le realizó a Violich Juan José Martín Frechilla (2004).

36 Con su aguda sensibilidad para las razones latinoamericanas, Albert Hirschmann explicaba la resistencia a aceptar el «modelo portorriqueño» recordándole a sus interlocutores norteamericanos que «nunca podrá demostrarse, de manera irrefutable, que ese desarrollo económico no se ha comprado al precio de una cantidad de independencia que otros países no están dispuestos a pagar»; ver "Abrazo versus coexistencia» (1960), en Hirschmann (1973: 168).

37 Sobre Rudofsky y Van Eyck, véanse los artículos publicados en el número de la revista Block dedicado al «Tercer Mundo» (del cual ya se ha citado un artículo de Liernur): Scott (2004) y Strauven (2004). Los libros de Edward Hall $(1951$; 1972) circularon en los años 1950 y 1960 como parte de un conjunto de búsquedas de ampliación de la experiencia urbana, entre las que podríamos citar, desde disciplinas y universos ideológicos muy diferentes, las investigaciones en diseño urbano de Kevin Lynch (1984) y las aproximaciones político-artísticas de la Internacional Situacionista en París (cfr. Sadler, 1998), en todos los casos, buscando refutar la reducción funcionalista de la ciudad a manos del modernismo.

38 Eduardo Neira Alva (1924-2005) es una figura muy representativa de los rumbos que comenzaban a tomar los arquitectos comprometidos en América Latina. Era concuñado de José Matos Mar (lo que ejemplifica de paso los círculos sociales estrechos dentro de los que estas transformaciones intelectuales se procesaban en nuestras «ciudades letradas») y también integraba las huestes modernistas del grupo «Espacio» (de allí su presencia en la reunión CIAM de Venecia), la plataforma de lanzamiento, como ya se mencionó, de la carrera política de Fernando Belaúnde Terry, a quien Neira también acompañó en la creación del partido Acción Popular. Realizó un posgrado en diseño urbano en Liverpool y a su regreso a Lima en 1953 hizo su primera transición de arquitecto modernista a funcionario en temas urbanos, incorporándose como Jefe del Departamento de Urbanismo del Ministerio de Fomento y Obras Públicas en el gobierno del general Odría -ese ejemplo de populismo autoritario y desarrollismo muy típico del período-, cargo que mantuvo hasta 1959, es decir, durante el gobierno centrista de Manuel Prado, en el que también integró la Comisión para la Reforma Agraria y la Vivienda (1956-57), mostrando la ubicuidad 
de los cuadros técnicos de Belaúnde (que había perdido las elecciones presidenciales en 1956). En 1961, Neira fue a dictar clases a Caracas, haciendo su segunda transición de funcionario de urbanismo a experto en planificación latinoamericana. Venezuela estaba atravesando un proceso de reorganización desarrollista de su sistema nacional de planificación y Neira decidió radicarse, formando parte del equipo de creación del Centro de Estudios del Desarrollo (CENDES), uno de los primeros centros de investigación y formación en temas de planificación urbana y territorial de América Latina, junto al economista chileno Jorge Ahumada, que acababa de dejar CEPAL; allí, Neira dirigió los Cuadernos del CENDES hasta que se fue a realizar un estudio de planificación regional en Bahia contratado por el Banco Mundial, haciendo su tercera y última transición a consultor internacional.

39 Las posiciones de Turner obtuvieron repercusión internacional en 1963, al preparar el número especial de la revista británica Architectural Design: «Dwelling resources in Latin America» (Turner, 1963). Ha publicado innumerables libros difundiendo sus experiencias, como Housing by People (Turner, 1976). En su artículo más conocido, Mangin (1967) impuso la fórmula por la cual las barriadas se convertían «de problema a solución».

40 Ver John Turner, "The squatter settlement: an architecture that works», Architectural Design $\mathrm{N}^{\circ} 8$, 1968, citado por Ballent (2004: 90) que analiza con agudeza la experiencia de PREVI, el concurso internacional de vivienda popular que se llevó a cabo en Lima en 1966 con apoyo de las Naciones Unidas y participación de algunos de los arquitectos mas importantes del mundo que pusieron en práctica un abanico de posiciones experimentales, tipológicas, tecnológicas y sociales, concitando por bastante tiempo la atención de la disciplina.

${ }^{41}$ Esta relectura neoliberal ha sido ya destacada en el artículo de Anahi Ballent (2004).

${ }^{42}$ Sobre la trayectoria de Morse (1922-2001) pueden verse los trabajos que se publicaron en la revista Punto de Vista: Myers (2002) y Gorelik (2002).

${ }^{43}$ El libro es de 1965, pero Hauser aclara en nota que su artículo contra Redfield fue una ponencia de 1955. Cabe señalar que estoy reduciendo el universo de críticas a las que tuvieron más ingerencia en el mundo del pensamiento urbano, porque en términos sociológicos y antropológicos, las posiciones de Redfield fueron discutidas profusamente desde más temprano, especialmente por latinoamericanistas, como muestra el análisis de Marsal (1967: 66-82).

44 Apoyándose en Everett Hughes, Benet (19631964: 5) caracteriza al estudioso urbano típico de Chicago como un «centauro americano», mitad sociólogo y mitad antropólogo romántico, cuya falla es tomar como modelo para sus análisis las pequeñas aldeas que sólo existen en Europa; y por eso, dice, los mejores estudios de Chicago son los que toman como tema los «fragmentos de esos mundos encriptados en las ciudades norteamericanas (como las Little Sicilies)», señalando los ejemplos de The Ghetto de Wirth y el clásico libro de Florian y Znaniecki sobre el campesino polaco en los Estados Unidos.

45 Valladares, que claramente se identifica con la experiencia de los Leeds, le dedica un muy interesante pasaje de su libro (Valladares, 2005: 112-113).

${ }_{46}$ Me refiero a la serie de libros abierta en 1961 por Los hijos de Sánchez (libro que produjo un escándalo enorme cuando se editó en México en 1964, incluyendo el alejamiento de Arnaldo Orfila Reynal del Fondo de Cultura Económica). De hecho, Lewis fue precisando el uso de la noción "cultura de la pobreza» para los casos de completa marginalidad urbana: "Cuando hay gente que en realidad pertenece a una sociedad más amplia y que tiene su propio lugar en ella, cuando piensa que puede triunfar y vivir según los valores de una sociedad mayor, cuando tiene sus propias organizaciones, entonces, no hay cultura de la pobreza, hay sólo pobreza»; ver la conversación de Oscar Lewis con K. S. Karol y Carlos Fuentes (1967: 20).

47 La cita es de Eduardo Neira, tomada de los debates suscitados por la ponencia ya citada de los Leeds, donde también se pueden encontrar intervenciones muy jugosas de Milton Santos y Alberto Urdaneta que expresan la primera y la tercera de las objeciones aquí enumeradas (Funes, 1972: 161-175); la segunda, la de la superexplotación, ha sido argumentada en términos consecuentemente marxistas por Emilio Pradilla (1982). De todos modos, vale aclarar que son apenas ejemplos puntuales de debates muy extendidos en el campo del pensamiento urbano del período.

48 Uso la expresión "polarizado» en el sentido en que la ha utilizado Francisco Sabatini (1977), equivalente a las posiciones más extremas de la marginalidad que la ven como enfrentamiento irreconciliable en el seno de la sociedad burguesa. Sabatini busca en su inteligente artículo mostrar el modo en que la ausencia de la «dimensión ambiental» explica buena parte de las limitaciones de las teorías «dualistas» y «polarizadas» sobre la marginalidad; como mis objetivos son bastante diferentes, mi clasificación también difiere en parte de la suya.

${ }^{49}$ Aníbal Quijano estudió Letras en la Universidad de San Marcos, Lima y sociología en FLACSO en Santiago de Chile, donde permaneció en los últimos años de la década de 1960 dictando cursos en el ILPES y realizando estudios para CEPAL. Allí desarrolló sus análisis sobre la urbanización dependiente, convirtiéndose en una de las figuras más reconocidas de la «teoría de la dependencia». Actualmente, reparte sus actividades académicas entre los Estados Unidos y Perú, y es uno de los principales animadores del Foro Social Mundial.

50 Manuel Castells (1942), sociólogo español formado en Francia, viajó a Santiago de Chile en 1968 invitado por FLACSO, y volvió en los primeros años setenta, en el momento del ascenso al poder del gobierno de la Unidad Popular, invitado por la Universidad de Chile, aunque también estuvo fuertemente en contacto con el Centro de Investigaciones en Desarrollo Urbano (CIDU), la institución fundadora de los estudios socio-urbanos en Chile, que se había creado en la Universidad Católica con fondos de la Fundación Ford. Allí desarrolló investigaciones sobre el movimiento poblacional y la urbanización latinoamericana y se convirtió en referente del pensamiento urbano de la nueva izquierda. Ver, por ejemplo: «Movimiento de pobladores y lucha de clases en el Chile de la Unidad Popular «, en Castells (1974a). Hacia los años 1980, ya instalado en los Estados Unidos, Castells se convirtió,con una orientación ciertamente diferente, en un referente de los estudios sobre redes y globalización.

${ }^{51}$ Paul Singer nació en Viena en 1932 y se radicó en Brasil en 1940. Es economista y fue miembro fundador en 1969 del Centro Brasileiro de Análise e Planejamento (CEBRAP). Su obra más importante en los temas urbanos es el libro Economía política de la urbanización (Singer, 1975) (la edición brasileña por el CEBRAP es del mismo año) que reúne un conjunto de artículos publicados durante los años sesenta. Ha sido Secretario de Planeamiento de la ciudad de São Paulo (1989-1992) y actualmente (2008) es asesor del gobierno Lula en temas de economía solidaria, su más reciente especialización.

52 Sabatini cita dos textos clásicos de Singer recopilados en Economía política de la urbanización: «Urbanización, dependencia y marginalidad en América Latina»y «Migraciones internas en América Latina: consideraciones teóricas sobre su estudio».

53 El libro salió editado en 1974 por II Mulino, de Bolonia, y en 1976 fue traducido al castellano en la colección que Germani dirigía en Paidós con el título de 
Urbanización, desarrollo y modernización. La introducción de Germani se titula «La ciudad, el cambio social y la gran transformación». El artículo de Redfield era de 1954, cuando ya había tomado cierta distancia de la «teoría del continuo», haciéndose cargo implícitamente de algunas de las críticas; buscaba presentar una tipología de ciudades en la historia, para entender desde la propia ciudad el problema de los diversos procesos civilizatorios. 